\title{
The Use of Design Automation Software by Government-Contracted Architect/Engineer Firms: A Status Report
}

by

Michael L. Golish

Carrie J. McCunn

Beth A. Symonds

Most Architecture and Engineering $(\mathrm{A} / \mathrm{E})$ design firms and Corps of Engineers District offices have found that computer-aided design and drafting (CADD) has a great potential for improving productivity, profitability, communication, and design quality. Yet, clients' demand for design and construction information created with CADD and delivered in a variety of specified computer formats can hinder scheduling, quality control, and profitability of A/E firms.

This phase of research collected information on the status and use of CADD by A/E firms to identify trends in hardware, software, CADD staffing and compensation, and trends in how design firms that use CADD have accepted this form of automation. Secondary objectives were to determine how CADD has improved design firm productivity, design quality, documentation, and profitability, and to note any outstanding problems associated with the use of CADD in the design process.

The second phase will review and analyze reports from the Army's Automated Review Management System (ARMS) and the Construction Evaluation Retrieval System (CERS) to determine how automation has affected Corps review procedures, and to locate and classify repetitive data that may be streamlined in future design and construction projects. 
The contents of this report are not to be used for advertising, publication, or promotional purposes. Citation of trade names does not constitute an official endorsement or approval of the use of such commercial products. The findings of this report are not to be construed as an official Department of the Army position, unless so designated by other authorized documents.

DESTROY THIS REPORT WHEN IT IS NO LONGER NEEDED

DO NOT RETURN IT TO THE ORIGINATOR 


\section{USER EVALUATION OF REPORT}

REFERENCE: USACERL Interim Report FF-93/06, The Use of Design Automation Software by Government-Contracted Architect/Engineer Firms: A Status Report

Please take a few minutes to answer the questions below, tear out this sheet, and return it to USACERL. As user of this report, your customer comments will provide USACERL with information essential for improving future reports.

1. Does this report satisfy a need? (Comment on purpose, related project, or other area of interest for which report will be used.)

2. How, specifically, is the report being used? (Information source, design data or procedure, management procedure, source of ideas, etc.)

3. Has the information in this report led to any quantitative savings as far as manhours/contract dollars saved, operating costs avoided, efficiencies achieved, etc.? If so, please elaborate.

4. What is your evaluation of this report in the following areas?

a. Presentation:

b. Completeness:

c. Easy to Understand:

d. Easy to Implement:

e. Adequate Reference Material:

f. Relates to Area of Interest:

g. Did the report meet your expectations? 
h. Does the report raise unanswered questions?

i. General Comments. (Indicate what you think should be changed to make this report and future reports of this type more responsive to your needs, more usable, improve readability, etc.)

5. If you would like to be contacted by the personnel who prepared this report to raise specific questions or discuss the topic, please fill in the following information.

Name:

Telephone Number:

Organization Address:

6. Please mail the completed form to:

Department of the Army

CONSTRUCTION ENGINEERING RESEARCH LABORATORIES

ATTN: CECER-IMT

P.O. Box 9005

Champaign, IL 61826-9005 
Public reporting burden for this collection of information is estimated to average 1 hour per response, including the time for reviewing instructions, searching existing data sources, gathering and maintaining the data needed, and completing and reviewing the collection of information. Send comments regarding this burden estimate or any other aspect of this collection of information, including suggestions for reducing this burden, to Washington Headquarters Services, Directorate for information Operations and Reports, 1215 Jefferson Davis Highway, Suite 1204, Arlington, VA 22202-4302, and to the Office of Management and Budget, Paperwork Reduction Project (0704-0188), Washington, DC 20503.

\begin{tabular}{l|l|l} 
1. AGENCY USE ONLY (Leave Blank) & 2. REPORT DATE & 3. REPORT TYPE AND DATES COVERED
\end{tabular} September 1993

Interim

4. TITLE AND SUBTITLE

The Use of Design Automation Software by Government-Contracted

Architect/Engineer Firms: A Status Report

4A 162784

AT41

SA-A02

6. $\operatorname{AUTHOR}(\mathrm{S})$

Michael L. Golish, Carrie J. McCunn, and Beth A. Symonds

7. PERFORMING ORGANIZATION NAME(S) AND ADDRESS(ES)

U.S. Army Construction Engineering Research Laboratories

PO Box 9005

8. PERFORMING ORGANIZATION REPORT NUMBER

Champaign, IL 61826-9005

IR-FF-93/06

9. SPONSORING/MONITORING AGENCY NAME(S) AND ADDRESS(ES)

Headquarters, U.S. Army Corps of Engineers (HQUSACE)

ATTN: CEMP-EA

20 Massachusetts Ave., NW.

Washington, DC 20020-1000

11. SUPPLEMENTARY NOTES

Copies are available from the National Technical Information Service, 5285 Port Royal Road, Springfield, VA 22161

12a. DISTRIBUTION/AVAILABILITY STATEMENT

Approved for public release; distribution is unlimited.

12b. DISTRIBUTION CODE

13. ABSTRACT (Maximum 200 words)

Most Architecture and Engineering (A/E) design firms and Corps of Engineers District offices have found that computer-aided design and drafting (CADD) has a great potential for improving productivity, profitability, communication, and design quality. Yet, clients' demand for design and construction information created with CADD and delivered in a variety of specified computer formats can hinder scheduling, quality control, and profitability of $\mathrm{A} / \mathrm{E}$ firms.

This phase of research collected information on the status and use of CADD by A/E firms to identify trends in hardware, software, CADD staffing and compensation, and trends in how design firms that use CADD have accepted this form of automation. Secondary objectives were to determine how CADD has improved design firm productivity, design quality, documentation, and profitability, and to note any outstanding problems associated with the use of CADD in the design process.

The second phase will review and analyze reports from the Army's Automated Review Management System (ARMS) and the Construction Evaluation Retrieval System (CERS) to determine how automation has affected Corps review procedures, and to locate and classify repetitive data that may be streamlined in future design and construction projects.

14. SUBJECT TERMS

architectural and engineering firms

CADD

government-contracted firms

design automation

18. SECURITY CLASSIFICATION
OF THIS PAGE
Unclassified
19. SECURITY CLASSIFICATION OF ABSTRACT Unclassified
15. NUMBER OF PAGES 44

16. PRICE CODE
OF REPORT

Unclassified 


\section{FOREWORD}

This study was conducted for Headquarters, U.S. Army Corps of Engineers (HQUSACE) under Project 4A162784AT41, "Military Facilities Engineering Technology"; Work Unit SA-A02, "Concept Analysis Tools." The technical monitor was Daniel Duncan, CEMP-EA.

The work was performed by Facility Management Division (FF), Infrastructure Laboratory (FL), U.S. Army Construction Engineering Research Laboratories (USACERL). The USACERL principal investigator was Beth Symonds. Alan Moore is Acting Chief, CECER-FF and Dr. Michael J. O'Connor is Chief, CECER-FL. The USACERL technical editor was William J. Wolfe, Information Management Office.

LTC David J. Rehbein is Commander of USACERL, and Dr. L.R. Shaffer is Director. 
SF 298

FOREWORD

LIST OF FIGURES

INTRODUCTION $\ldots \ldots \ldots \ldots \ldots \ldots \ldots \ldots \ldots \ldots \ldots \ldots \ldots \ldots \ldots \ldots$

Background

Objectives

Approach

Scope

Mode of Technology Transfer

2 TRENDS IN DESIGN AUTOMATION

Hardware

Software

Design and Construction Reviews

CADD Staffing and Compensation

Acceptance of Automation

3 BENEFITS OF DESIGN AUTOMATION

Productivity

Profitability

Communication/Coordination

Quality Design

Quality Documents

Misconceptions about CADD

Transfer of CADD Data

Getting Paid for CADD

Training

Updates

CADD Management and Support 



\section{THE USE OF DESIGN AUTOMATION SOFTWARE BY GOVERNMENT-CONTRACTED ARCHITECT/ENGINEER FIRMS: A STATUS REPORT}

\section{INTRODUCTION}

\section{Background}

Many factors combine to make Architecture and Engineering (A/E) a complex practice that presents serious challenges to $\mathrm{A} / \mathrm{E}$ managers: stiff competition, rapid changes in technology and regulations, increasing litigation, tight production schedules, and stringent budgets imposed by clients. Clients' demand for design and construction information created with computer-aided design and drafting (CADD) tools and delivered in a variety of specified computer formats can also hinder scheduling, quality control, and profitability. Many Corps of Engineers District offices and their A/E contractors approach these problems by using CADD software to produce design documents quickly, accurately, and to their clients' specifications. Probably the greatest drawback in using CADD tools is the time required to effectively integrate the software into design and production processes (Fallon 1988b).

In spite of this obstacle, most design firms have found that CADD has a great potential for improving productivity, profitability, communication, and design quality. Still, CADD is not a "cure-all"; principals and managers must resolve many problems within the constraints of limited time and capital. A better understanding of the problems facing design firms, and of their successes and failures in using CADD to resolve those problems, can help A/E firms better adapt themselves to automated methods, and can help CADD designers better meet the needs of program users.

\section{Objectives}

General objectives of this phase of research were to investigate and summarize the advantages and problems of CADD use, as perceived A/E contractors. More specific objectives were to: (1) discover and analyze issues conceming the nature of design automation, (2) collect information on the status and use of CADD software as a design automation tool, (3) address trends in hardware, software, and CADD staffing and compensation, and (4) investigate trends in how design firms have accepted this form of automation. Secondary objectives were to determine how automation has improved design firm productivity, design quality, documentation, and profitability, and to note any outstanding problems associated with the use of CADD in the design process.

The second phase of research will review and analyze reports from the Army's Automated Review Management System (ARMS) and the Construction Evaluation Retrieval System (CERS), two programs that U.S. Army Corps of Engineers (USACE) districts use to electronically track comments made during the construction and review process. This review will determine how automation has affected Corps review procedures, and will locate and classify repetitive data that may be streamlined in future design and construction projects.

\section{Approach}

A literature search was conducted of current and past automation surveys, CADD liability cases, CADD productivity, design reviews, design errors, and modifications. The American Institute of 
Architects (AIA) was contacted for information on design liability and errors that may result from automation.

A design automation survey was designed and distributed at an Architectural Automation Task Group meeting (AATG), 19-20 September 1991 (Appendix A). The AATG is a representative group that serves as an advocate for improved use of CADD for architectural applications. The minutes and proceedings of the AATG meeting were reviewed for practical insights-from the user's point of view-into the use of CADD.

Results from the present survey were compared with the results of two previous, more extensive surveys: (1) a survey by Practice Management Associates, Ltd. (PSMJ), and (2) a hardware/software survey conducted by the U.S. Army Construction Engineering Research Laboratories (USACERL) at the U.S. Army Corps of Engineers (USACE) Architectural Conference of A/E design firms in 1987. This comparison noted similarities, differences, and parallels in government and private sector automation practices.

Reports from ARMS and CERS were reviewed to locate and classify repetitive data that may be streamlined in future design and construction projects, and to determine how automation has affected Corps review procedures.

\section{Scope}

A/E firms discussed in this report are either public or government-contracted firms. Governmentcontracted firms are defined as those whose workload is at least 60 percent comprised of government contracts. Public firms are those whose workload is at least 60 percent in the public arena.

\section{Mode of Technology Transfer}

The results of this study will form the basis for planned research that will analyze and categorize comment reviews from the ARMS database to determine the extent to which automation and standardization have reduced errors in the design and documentation process. This information will be forwarded to the Corps of Engineers Federal Automation Task Group (FATG). 


\section{Hardware}

\section{Cost Decreases}

Cost is possibly the most visible and actively changing trend of computer hardware systems. The results of the three surveys show that the costs of hardware systems have decreased while the amount of money firms spend on hardware has increased. This implies that firms are buying more hardware systems than in previous years.

The PSMJ survey indicated that, between 1981 and 1990, the cost of a single workstation had fallen from $\$ 42,000$ to $\$ 8171$ (16 percent of its 1981 cost). Furthermore, while CADD hardware revenues are decreasing, the number of systems being installed is increasing. During the 1980s, CADD system revenue dropped by as much as 12 to 40 percent, while at the same time, CADD system installation increased (Fallon 1988a). Figure 1 shows the decrease in workstation cost over the past 7 years.

The PSMJ survey also showed that the architectural engineering firms doing work for the government invest a median of $\$ 60,000$ on hardware systems and $\$ 111,000$ for total CADD costs. The annual sum of money spent for hardware systems by these surveyed firms was $\$ 6517$. The types of firms most likely to make substantial investments in CADD were large firms, multidisciplinary firms, and specialty firms.

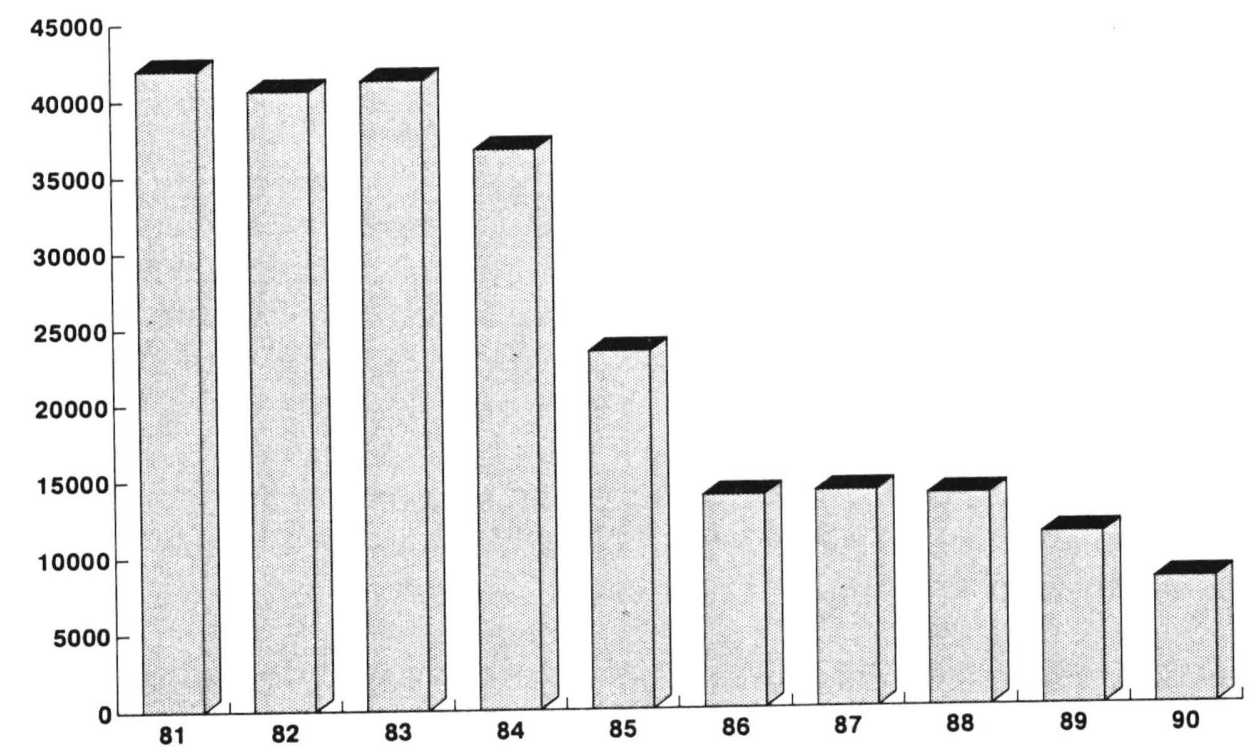

Figure 1. Average Workstation Cost. 


\section{Systems Used}

When design automation hardware first became available, it was large and quite expensive. Through time, smaller, less expensive, and more efficient computers have been developed. Larger and more expensive computers are still available, but the current trend is to substitute many small personal computers (PCs) for one large workstation. The three surveys indicated that smaller firms tend to purchase personal computers, while larger firms invest in the more expensive workstations. The present survey also showed that more firms are investing in personal computers than workstations or mainframes (Figures 2 and 3).

An analysis of the brands of personal computers used shows that the IBM personal computer is the most popular, followed by the Zenith computer. Several other personal computers were as popular as Zenith (Figure 4).

\section{Demand for Hardware}

It is estimated that even though a majority of firms use computers 50 to 78 percent of the time, only 79 percent of the firms using automation intend to expand their systems. An additional survey of building contractors showed that only 70 percent of them said they would increase their computer inventory in the next few years; however, none of them said that they would decrease their computer inventory (Faulkner 1988). The three studied surveys showed that 79 percent of the firms owning design automation hardware plan to expand their systems in the year 1991.

The greater demand for computer hardware is generally matched by computer availability. The present survey (Appendix A) showed that all the respondents had access to computers and used them 78 percent of the work day. Only nine respondents had access to a workstation that was used only 15 percent of the time. Coordination of the responses from the other two studied surveys showed that the ratio of people using computers at work to those who do not was 5.4:1. Still, the survey showed that of 54 people, only 17 had terminals at their desks.

\section{Software}

\section{Definition}

For this study, software was classified into three categories: graphic systems, alphanumeric databases, and expert systems. Graphic systems are 2- or 3-dimensional interpretations of a database of numbers. Alphanumeric databases are capable of manipulating the information within the database, and expert systems allow for deductive reasoning and learning. Expert systems also predict the accuracy of their results (Peltz 1988).

The common trend among architects and engineers is to combine the first two software categories in an effort to produce an expert system, even though the combination of these two systems cannot fill expectations of a true expert system.

There are several reasons for substituting a combined graphic/database system for a true expert system. First, expert systems are more expensive than the combined substitute; on the surface, the substitute is a cost-efficient alternative to purchasing an expert system. Second, expert systems are complicated and can be difficult to learn; graphic and database systems tend to be relatively simple and familiar. Lastly, architects and engineers may actually meet their needs with the first two types of software. 


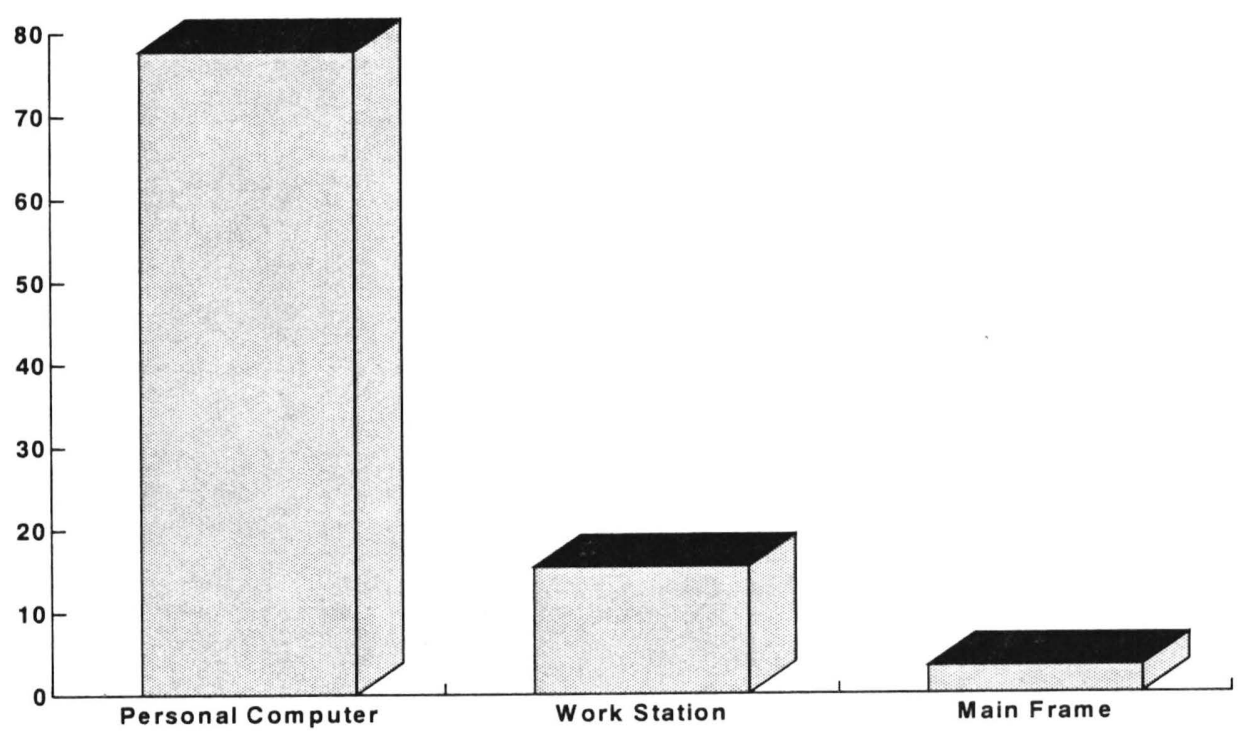

Figure 2. Hardware Used.

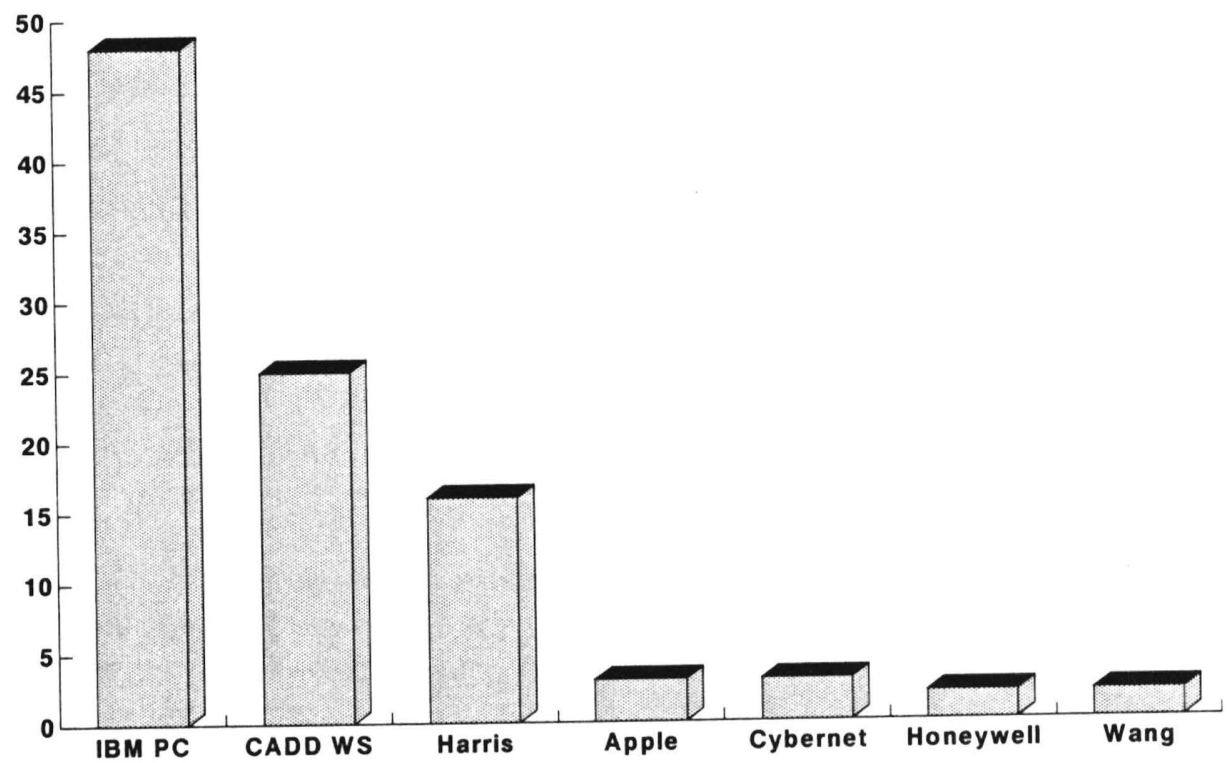

Figure 3. Systems Used. 


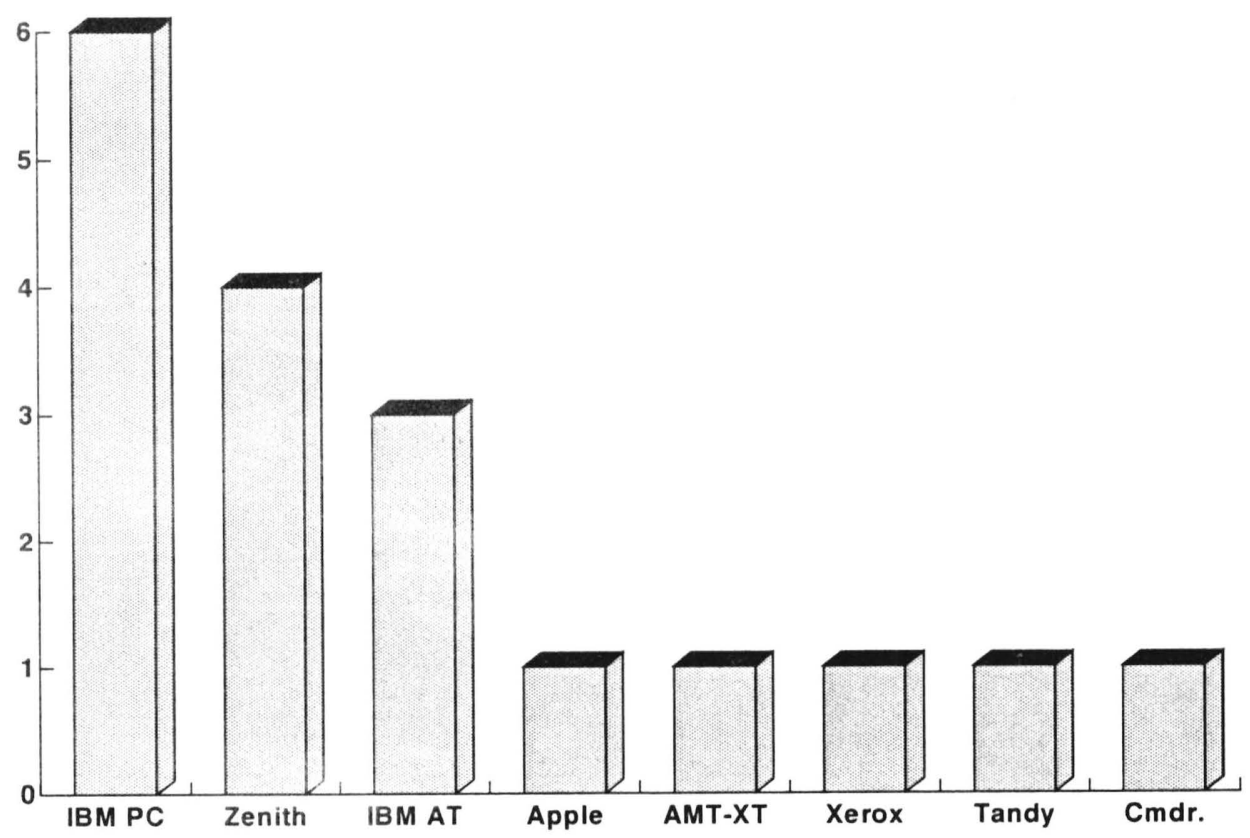

Figure 4. Personal Computers Used.

\section{Maintenance}

Maintenance agreements for software and hardware are growing in popularity because they provide assurance for nonexperienced users. Thirty-nine percent of the firms surveyed spend approximately $\$ 6665$ (10 percent above the original cost of software) for a software maintenance agreement. Governmentcontracted firms are more likely to purchase software maintenance agreements than commercial firms.

Cost

Cost is always a concern when purchasing or budgeting for computer systems. Costs for computer hardware have been decreasing: 60 percent for mainframes, 40 percent for minicomputers, and 20 percent for micro-computer hardware (Faulkner 1988). The increased costs for software may be attributed to the great demand for the many available variations of software, and the cost of development and support of complex software systems.

A/E firms tend to spend around 5 to 7 percent of their overhead on CADD systems and software. The exact percentage of overhead spent is affected by firm type, size, and location. Currently, public firms pay more for software than do government firms. For initial software purchases, firms contracted by the government spend an average of $\$ 12,000$ while public firms spend approximately $\$ 60,000$. Annual costs are lower but roughly parallel original costs; public firms spend about $\$ 14,547$ and government firms spend an average of $\$ 2000$ on annual costs. Public firms are not the only ones that invest heavily in CADD system software. Large firms, multidisciplinary firms, multioffice firms, and mainframe-based firms also spend a large part of their overhead on software. 
The current economic recession has affected the amount of money spent to update software systems. The northeast United States has been most affected by the recession, and consequently shows the lowest CADD software spending for 1991 (Practice Management Associates 1991).

\section{Expansion}

Once system costs are budgeted, the probability of being able to expand the system software can be determined. Firms will increase their personal computer software by 84 percent and their workstation software by 75 percent of the original software cost. The percentage of software expansion is increasing; however, the number of firms expanding their software are decreasing (Figure 5).

This means that fewer individual firms are increasing their software systems in larger single purchases. This represents an overall decrease in amount spent, but an increase in the amount of software purchased, a phenomenon at least partially credited to the current economic recession. Of government offices surveyed, 91 percent are adding CADD software and 82 percent are adding workstation software.

Even with all of this expansion, many firms that could benefit from using CADD systems still do not possess or use the software. Small firms (strictly architectural firms, government-contracted firms, and engineering consulting firms) are the least likely to use computer software to do design and quantity estimating. Firms specializing in transportation are the most likely to do design and quantity estimating on the computer. Only 45 percent of some 35,000 architectural firms have even acquired a CADD software system (Fallon 1988a).

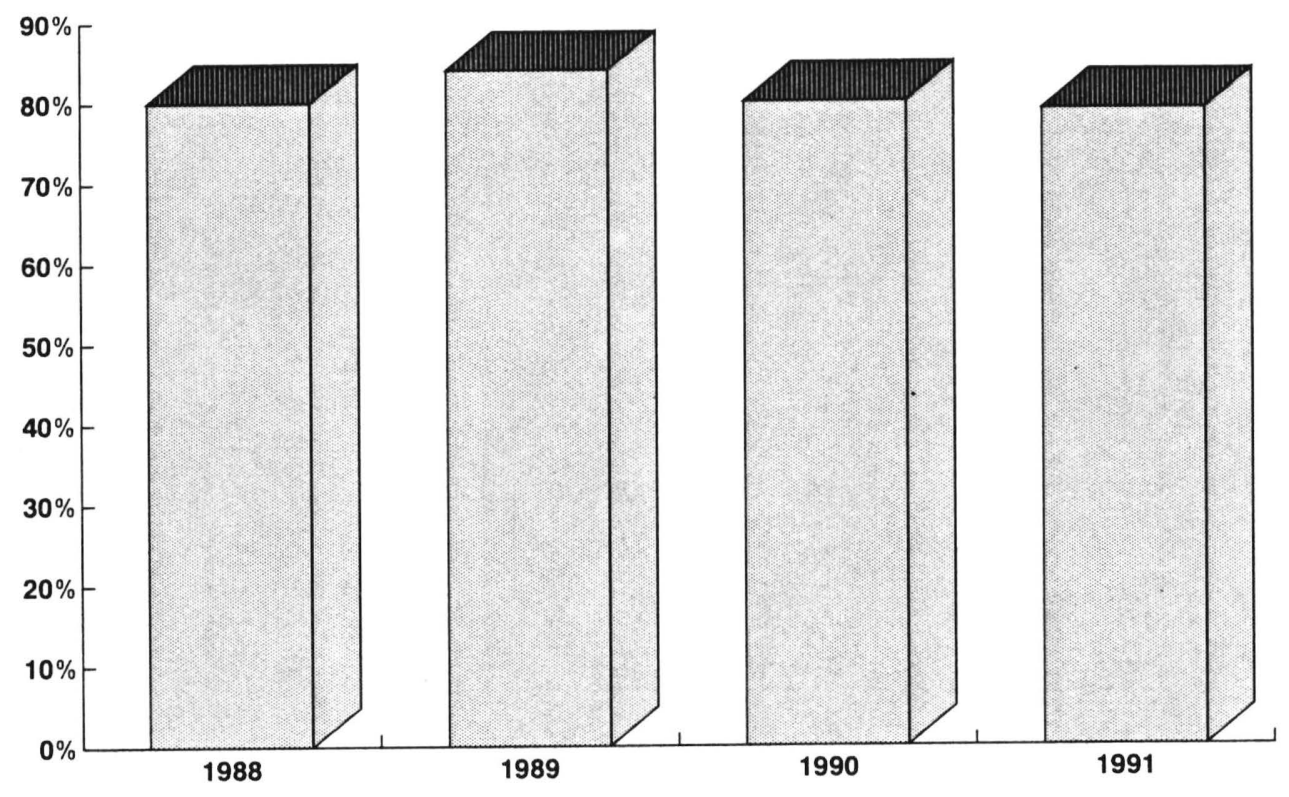

Figure 5. Software Expansion. 


\section{Applications}

A/E firms use only a minority of the vast amount of computer software applications available to them today. Drafting, detailing, scheduling, design, and word processing are the most popular applications used by public firms. Popular applications for government-contracted firms are: drafting, detailing, scheduling, design, client presentations, and material specifications. Drafting, design layout, working drawings, details, and scheduling are the activities that the respondents would most like to automate. Resource libraries are the only elements that respondents felt should not be automated. Lastly, HVAC design, mechanical design, resource management, database archiving, facility management, and lighting design are the least popular candidates for automation (Figure 6).

One source reported that software applications still needed include: estimating, job cost, accounting, and scheduling (Faulkner 1988). Accounting spreadsheets, payable/receivable spreadsheets, payroll spreadsheets, general ledger notation, job cost estimating, and CAD-CAM are the most popular applications used by building contractors. Note that this source was concerned primarily with contractors' special software needs, which are different than the software needs of government architectural offices.

New environments need to be developed to complement the many new software applications. These environments must be capable of supporting object-oriented CADD, mobile experiments, and standard design.

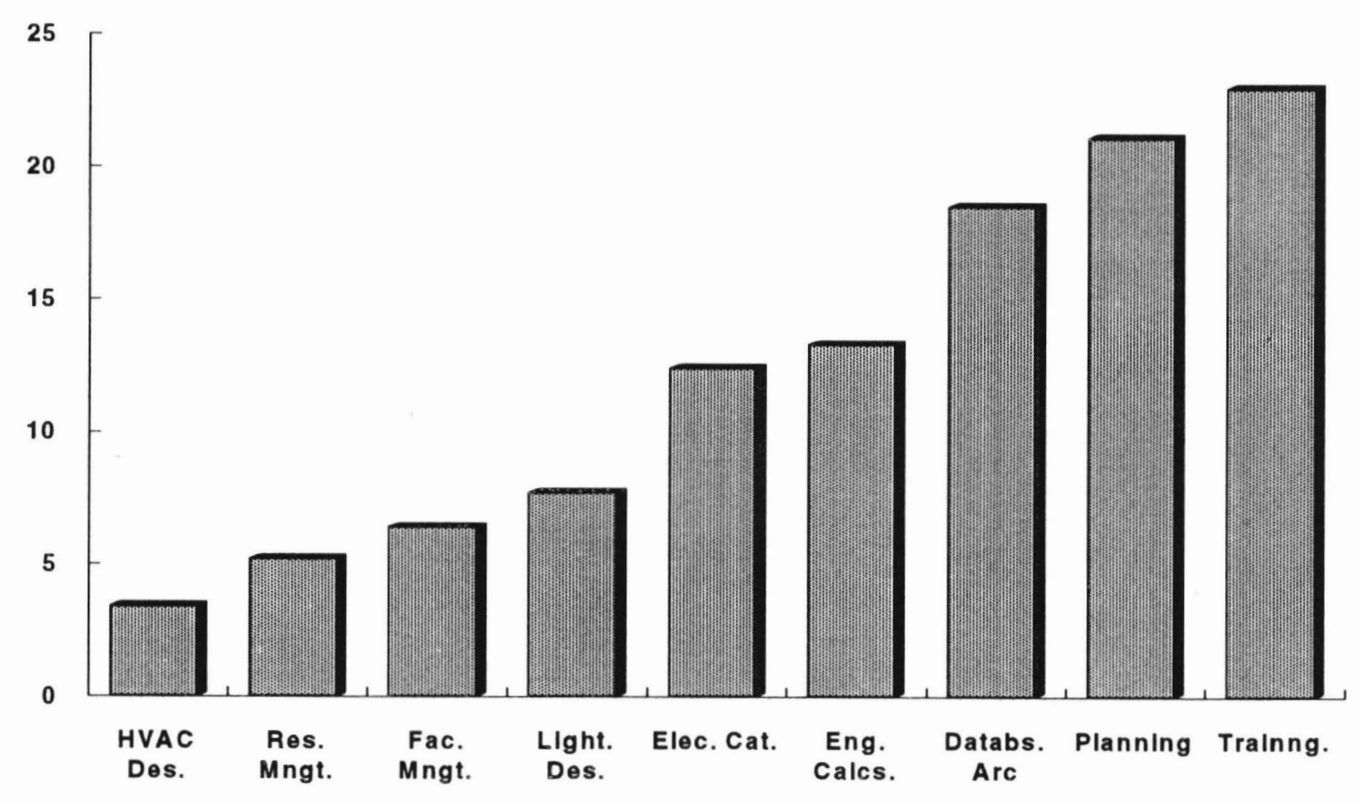

Figure 6. Software Preferences. 


\section{Essentials}

Many computer users are demanding better and more completely developed software. Most software is designed in such a way that one package automates a single task instead of an entire process. This is undesirable because firms need to buy many mutually incompatible software packages to fully automate their offices.

A complete software package should contain certain characteristics: ease of use, efficiency, flexible graphic input, quality graphic output, and good documentation. The most desired qualities in a software package by the Corps include compatibility across all systems, standardized storage, ease of use, and userfriendly interfaces.

\section{Design and Construction Reviews}

Many new software programs have been developed to satisfy the demand to automate building design and construction. The Army Corps of Engineers developed two programs to improve the construction and review process: the Automated Review Management System (ARMS), and the Construction Evaluation Retrieval System (CERS).

\section{Automated Review Management System (ARMS)}

The Automated Review Management System is a database used by the Corps of Engineers during each design phase of a construction project to review construction documents. The advantages of this application are that: (1) the transmittal of documents takes only minutes, (2) printouts are clean and concise, (3) comments can be accessed by all contributers and reviewers before they are released, and (4) all review comments can be managed together.

The procedure for using ARMS is simple. First, the user downloads the comments so that a response can be written. The responses are written and then uploaded and forwarded from the review manager to the project manager, who then sends them to the architect or engineer. There is a very large database of review comments of various stages of design for many different projects. A review of these comments showed that the most frequent comments relate to government procedures, and were primarily based on changing the drawings and construction specifications to conform with government procedures.

A previous study (Lozar 1984) analyzed the ARMS database comments. The present study determined changes in the frequency and tendencies of the ARMS comments between 1984 and 1992. Both studies were divided into three categories: building index, problem type, and construction specification. The building index study focuses on the element of the building structure being addressed in the comment. Comments typical to this study were:

- Compact the stabilized aggregate base course to 100 percent as in specs.

- Column locations do not interfere with access to waste cells?

- Indicate how metal studs are supported.

The construction specification study divides comments into the divisions of standard specification documents. Typical comments in this study are:

- $\quad$ Bidding schedule 3D and 3E- all project specs. must contain bidding schedule.

- No geotechnical aspects considered.

- Finish other than sealant on CMU? 
The problem type study was based on the the Lozar study. Frequent comments in the present study were:

- Coordinate plans and specifications regarding barrow and disposal sites.

- Ducts and AHU location not consistent with mechanical drawings. Coordinate.

- Check connection to 4X6 to pipe column.

Note that the analysis done for the present study was limited to 18 projects, whereas the Lozar study included 28 projects. The present study was done to form a basis for comparison and further research.

The Lozar study indicated that the most frequent comments were about the electrical concerns (17.2 percent), followed by HVAC plans (16.1 percent), and comments on the structural frame (10.2 percent). The new analysis showed that the majority of the comments focused on problems with the specifications (25 percent), followed by interior construction (17 percent), and the structural frame (13 percent). Figure 7 shows a comparison of the two studies.

The two studies obtained very different results. The Lozar study showed that most comments related to problems with coordination between disciplines and documents ( 95.5 percent), followed by calculations or simulations (2.2 percent). Omissions, deletions, checking and verifying, and errors all received less than 1 percent of the comments. The present study reflected a more even dispersal of comments. The most frequent comments found in the present study were concerned with checking and verifying parts of the design and construction ( 25 percent), followed closely by coordination (18 percent), and deletion (17 percent). The results (Figure 8 ) show a need to improve communication between those involved in separate steps of the design process.

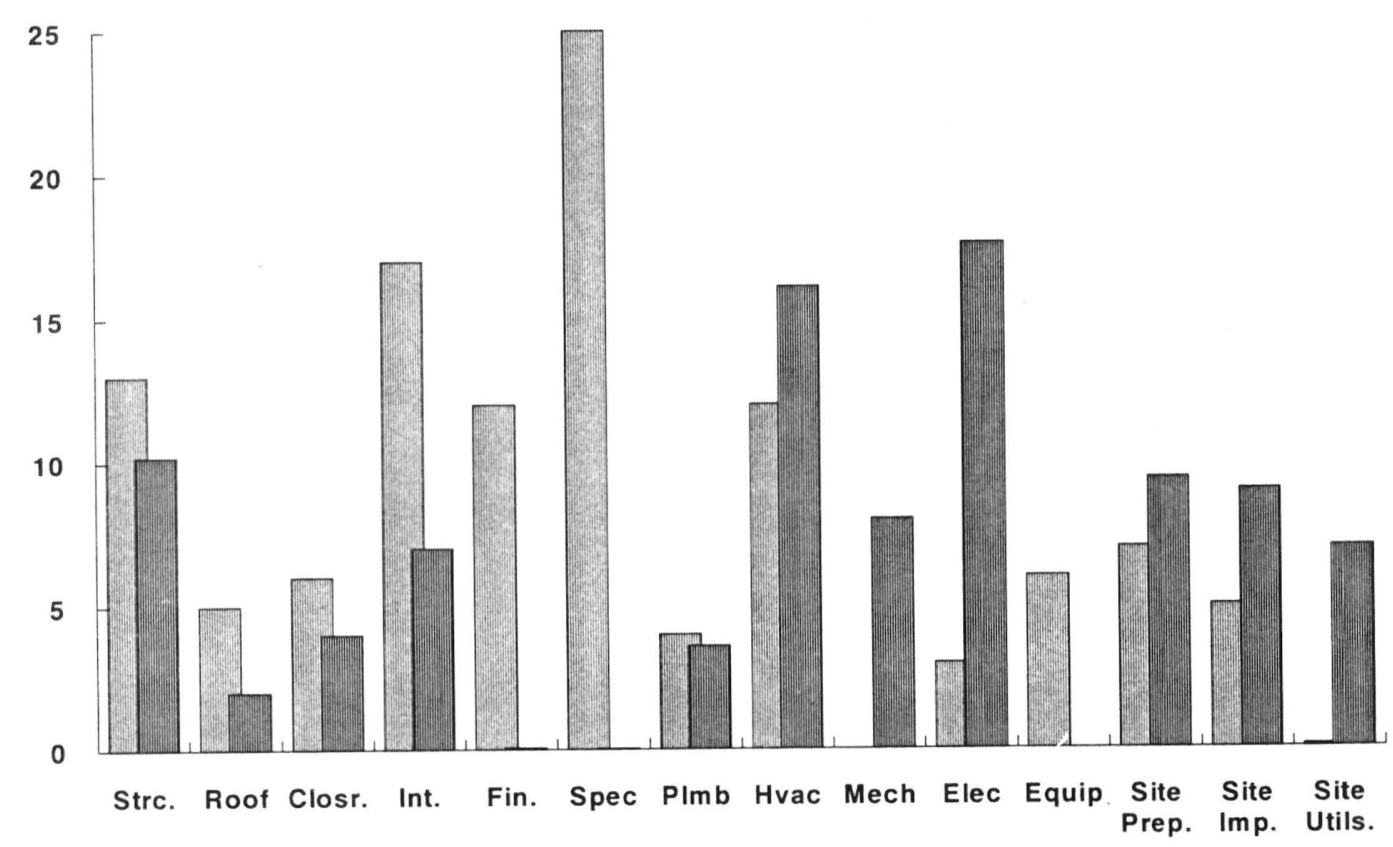

Figure 7. Building System Index Study Comparison. 


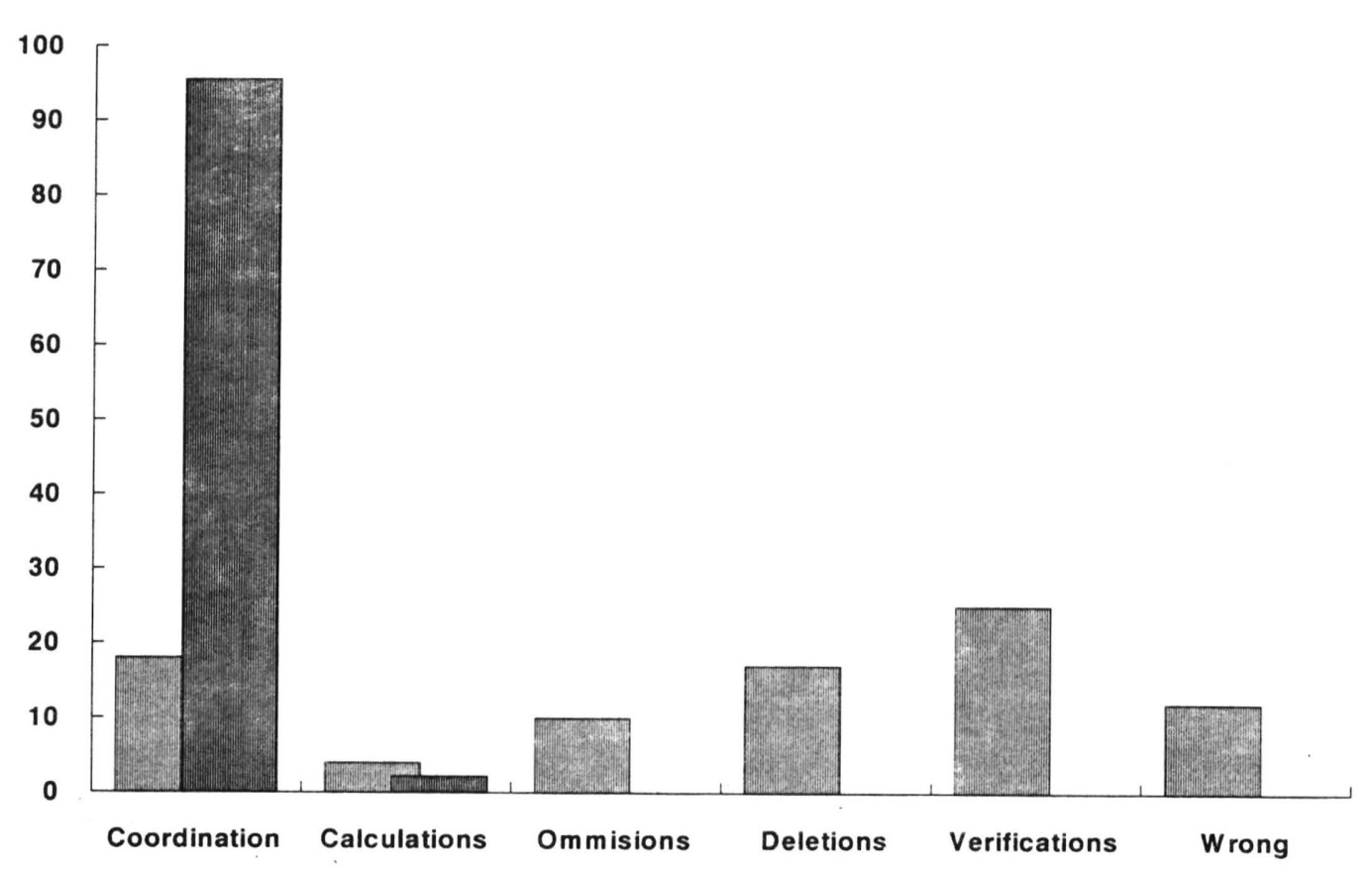

Figure 8. Problem Type Study Comparison.

The Lozar study shows that most of the comments on construction specification relate to sitework (22 percent), follcwed by concrete (10.6 percent). None of the other categories in the present study had over 6 percent of the comments. The present study showed a more even distribution of comments. The most frequent comments related to general requirements (14 percent), followed by finishing (13 percent), and sitework (12 percent). Figure 9 shows a comparison of the two studies.

\section{Construction Evaluation Retrieval System (CERS)}

The Construction Evaluation Retrieval System is a computer-based database developed in 1979 that contains information relating to design and construction evaluations, and that includes comments about design deficiencies, construction quality, and construction procedures. Unlike ARMS, CERS stores comments for construction phases only, although it may also reflect design errors.

CERS electronically collects input from a Design Construction Evaluation (DCE) trip and arranges the data and comments into a useful format. The system can then extract useful, well-organized data, lessons learned, and repetitive observations for use in future design and construction projects.

The CERS database is designed to present and reference comments in several ways. Information can be referenced to highlight past problems of a particular facility, comments from a certain time period, performance of a particular contractor, or the design deficiencies of a specific construction detail. 


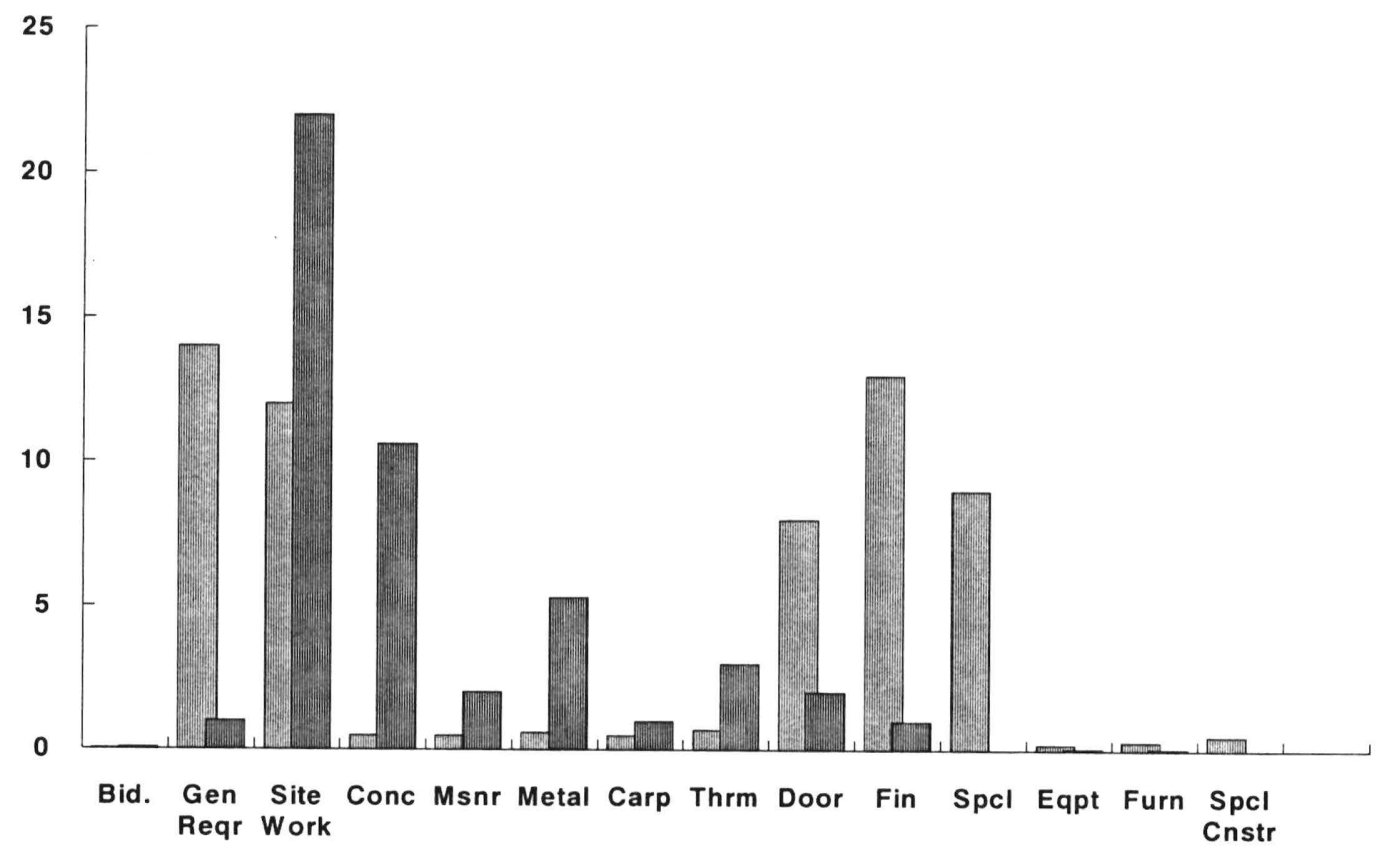

Figure 9. Construction Specification Study Comparison.

The following comments were referenced through the reinforced masonry specification number." The project, at the point these comments were made, was still in the construction phase, so many of the comments refer to construction changes:

An excessive number of chopped CMU units have been placed in area which will remain exposed. Despite patching and application of block filler and paint, many of these patched block will remain noticeable. Use of chipped block is prohibited in specification section 04230, Par. 7.14, 12.1, and 14.1.

Efflorescence, evident on exterior brick work at Fort Chaffee and Little Rock AFB, as well as at other Corps projects in other districts gives cause for concern. FE'S, BCE'S and DEH'S at these installations have leveled criticism at the corps for not correcting or controlling this widespread problem.

Detail B/S/S on drawing S-2 shows u-shaped units for lintels over openings in exterior walls of pump room. Specs. Sec. a 12.2.5 allows open type bond beam units. Building is construct with open units. Local manufacturers will not produce a u-shaped bond beam unit in split faced blocks.

Block color varies, joint thickness variation exceeds maximum concrete splatters on masonry block, excessive cracking of mortar at joints, cracks in block and mortar extend from base to roof on AMU $\# 1$, and AMU \#2 and AGE.

\footnotetext{
* All of the cited comments were taken from the reinforced masonry specification of a specific project. These comments are a small portion of the database of comments that holds comments from all building and design reviews.
} 
Contract drawings detailed reinforced masonry, Specs were silent on reinforced masonry. CEGS 04200 had been used instead of CEGS 04200.

Section 04230 Par. 12.1.3 required hollow metal door frames and spaces around to be filled with grout. Some door frames were not completely filled with grout.

Metal door frames are not filled with mortar as required by specs.

No sample reinforced concrete masonry panel constructed.

Lintels over 2 entrances used bond beam block in instead of lintel block. Reference sheet 26 (S-2). Typical lintel details.

ARMS and CERS play an essential part in completing the design automation process. When fully used, feedback from these databases can foster efficient communication between designers, engineers, and contractors to save both time and money.

\section{CADD Staffing and Compensation}

CADD training and experience has become a large factor in evaluating possible CADD staff. Only 6 percent of the A/E firms in the PSMJ survey indicated that CADD experience was not a factor in hiring decisions, whereas 80 percent prefer and 12 percent require CADD experience in new hirees. This is an increase over last year's PSMJ survey, demonstrating that A/E firms are becoming more interested in hiring experienced CADD staff.

A/E firms were surveyed on compensation levels for professionals, technicians, and drafters with similar experience and skill levels. CADD-trained staff were compared to non-CADD-trained staff to determine the relative value of CADD training. The comparison showed that some firms pay more for CADD-trained staff, although not in all staff categories. CADD-trained staff at the professional level or above were not additionally compensated, whereas CADD-trained staff below the professional level were more likely to be paid at a higher premium for the specialized training. The survey also indicated that draftsmen receive the highest compensation in engineering and government sector firms. This may explain the decreasing number of government-employed draftsmen.

\section{Acceptance of Automation}

A/E firms are quick to accept aspects of automation that are economical and easy to implement. On the other hand, these firms hesitate to commit to the cost of completely automating their offices, and are therefore slow in fully accepting automation. Only 79 percent of surveyed architectural firms intend to improve their CADD systems this year, a trend that continues a declining pattern begun in 1988 .

The number of firms using CADD on projects has increased by 10 percent every year since 1988 to a present level of 70 percent. Even though more firms are using CADD, there are many reasons they have not fully accepted automation. Fully accepting automation improves productivity, but only through improved system capabilities and better CADD management. It can be difficult to coordinate CADD with other software packages currently in use. For most firms, adding a CADD package means hiring a CADD specialist (at added expense), or expanding the responsibilities of an in-house staff person, a strategy that often fails. Finally, accepting automation implies staying aware of current changes and advancements in computer technology. Keeping current with rapid changes in computer technology is almost a daily task. 
Some applications are still not being fully utilized: facility management software programs are used only 22 percent of the time; 3D modeling, 34 percent; and quantity estimating, only 42 percent. Also, other applications like CERS and ARMS, are not being used to their maximum capabilities. Even though the acceptance of automation is well underway, it will still take time and full commitment for A/E firms to fully accept automation. 


\section{Productivity}

Design firm productivity is a gain "measured through an increase in revenue from the same amount of labor resources used or from reduced time to perform a task with CADD assistance" (Practice Management Associates Ltd. 1991). The majority of respondents in the three reviewed surveys agree that CADD does improve productivity. However, the PSMJ survey determined that it takes a substantial amount of time before firms obtain significant productivity gains. Figure 10 shows the average productivity gains of design firms relative to the number of years the system has been in place. In general, large firms of over 500 employees noted higher gains than small firms. Architecture and architecture/interior design firms reported the lowest gains.

The PSMJ survey found that users with graphic workstation-based systems reported higher productivity gains than did those with PC-based systems. However, findings show that networked PC systems recorded higher productivity gains than standalone PC systems. Also, minicomputer and mainframe systems are being moved out to make room for second generation CADD systems. In the case of the Corps of Engineers, most VAX machines are only being used for archiving or storage as they are replaced by the next generation of Intergraph workstations.

CADD operators, engineering technicians, and architectural technicians from Huntsville, AL and Vicksburg, MS, in responding to the questionnaire distributed for the present study, emphasized that automation increased productivity. Many respondents reported that the computer made drafting easier because modifications were simpler to make, and because symbols were uniform and easy to access from symbol libraries. The respondents also stressed that increased productivity was not immediate, but occurred only after the computer became more popular and easier to use. Others stated that the extra time saved by better productivity was used to provide more documents (Grim 1990).

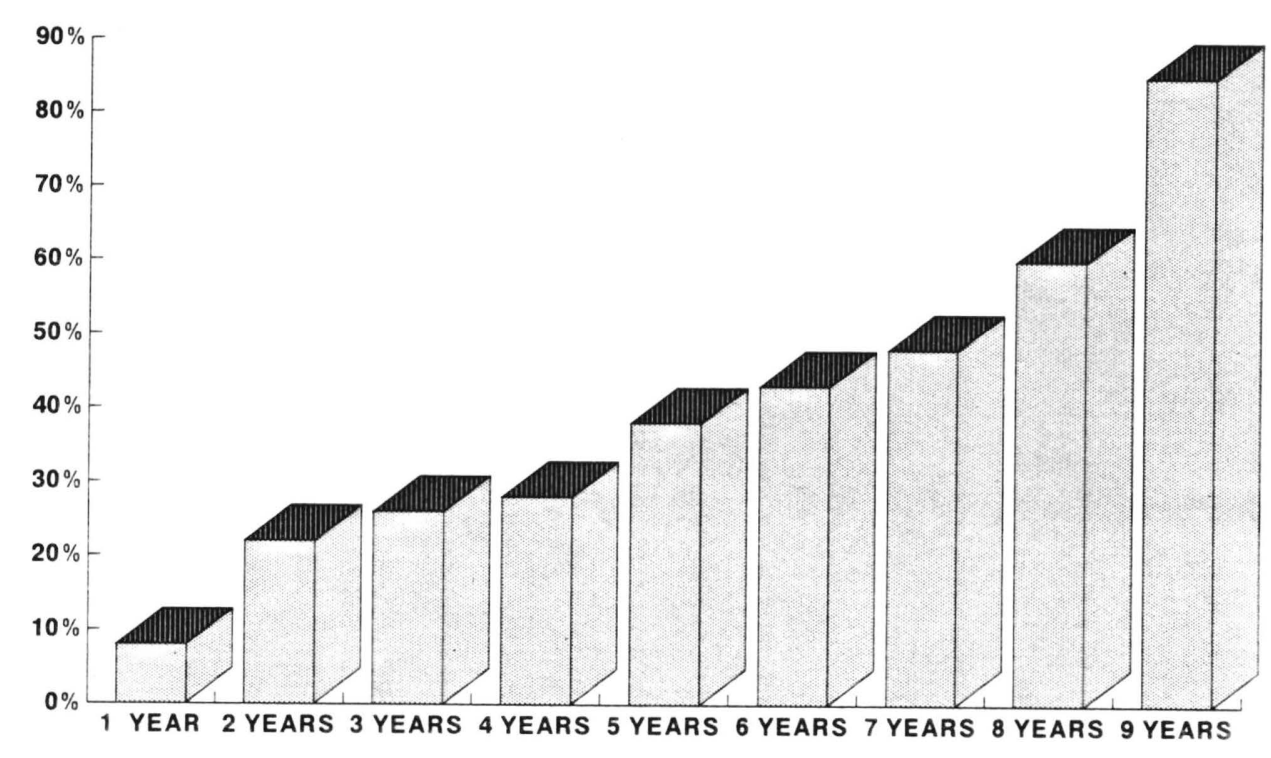

Figure 10. Average Productivity Gains By Years of Having System. 


\section{Profitability}

The PSMJ survey showed that, in 1988, users believed that CADD had a negative impact on profitability, but the present survey shows that 87 percent of private firms and 81 percent of governmentcontracted firms state their CADD investments have proven to be profitable. In general, design firms seem to believe that productivity (and profitability) gains as experience increases. Large firms (over 300 employees), architectural and interior design firms, and firms with housing clients are the most confident that automation results in greater profits. The least confident firms are small firms (1 to 25 employees), firms in the West, and government-contracted firms. Figure 11 shows the percentages of design firms that expressed confidence in CADD's ability to increase their profits.

\section{Communication/Coordination}

Results from the three studied surveys show that communication has been simplified through automation. A majority of the survey respondents believed that automation improved the coordination of work between project members because they could electronically stack the drawings and check for interferences and mistakes. They also felt that automation helped better inform workers of changes to the project. Finally, a majority of the respondents felt that it was easier to communicate and swap data with their consultants by exchanging disks.

The present survey showed that the level of communication has increased over the past year through the exchange of data files. Eighty-four percent of surveyed design firms provide clients with CADD data, and 92 percent have shared CADD data with other consultants. The Use and Needs survey (Lawrie, Bahnfleth, and Morton 1990) indicated a 45 percent decrease in required drawing corrections. This decrease exists because of the automated communication and coordination of the production of the drawings.

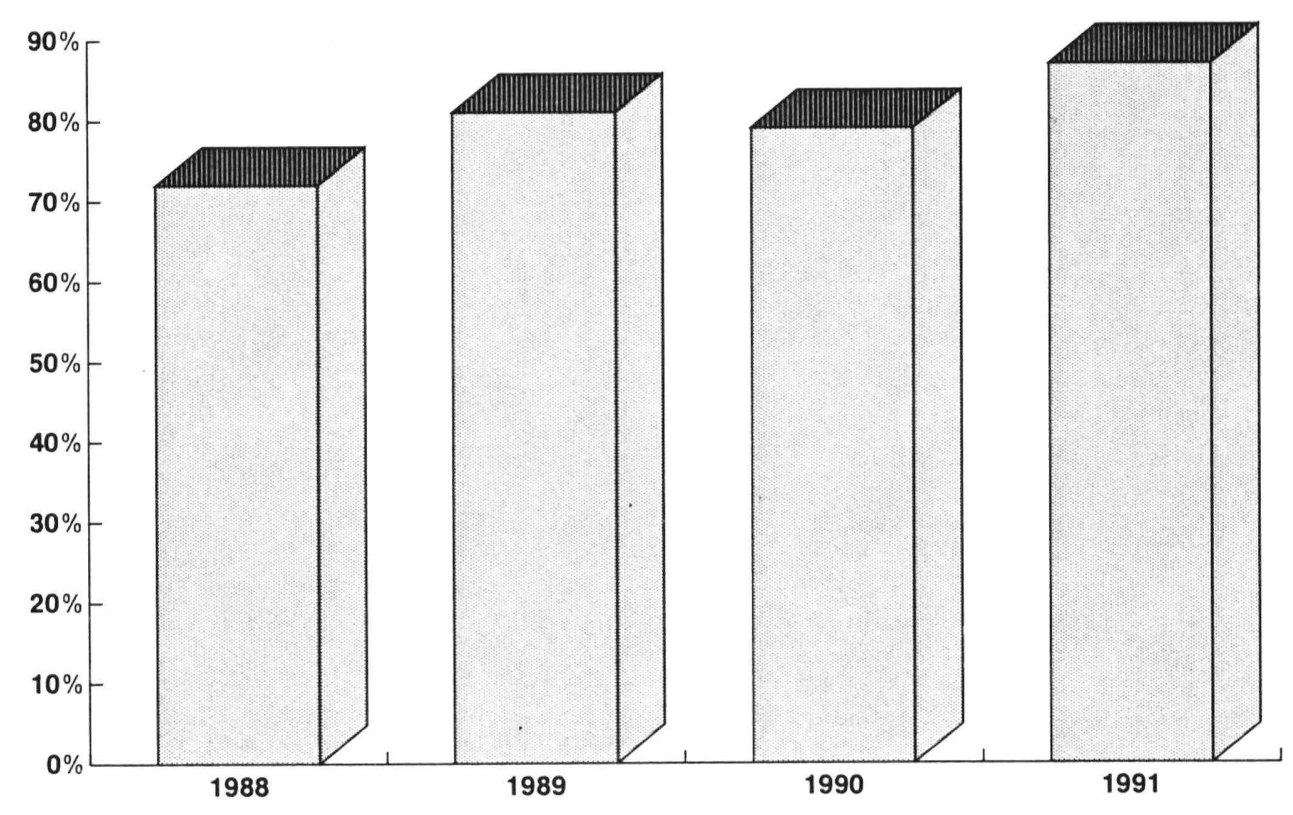

Figure 11. Firms Profiting from CADD. 
These percentages have increased over the past year showing that communication during the design process increasingly relies on computers.

\section{Quality Design}

One of the survey respondents stated that, "Automation improves the clarity of the job. Time improves the quality." More time may be spent on design alternatives because automation reduces the time spent on many repetitive tasks. This results in better design decisions and a better design. Most survey respondents stated that having the opportunity to develop design alternatives helped them produce a better quality design. However, being able to produce multiple design alternatives is not the only way automation improves the quality of design.

Another important factor is the increased quality of design is three-dimensioal (3D) visualization. The respondents to the surveys mentioned many ways in which 3D visualization helped improve their designs. Many of the respondents noted that 3D modeling allowed numerous views to be generated in perspective; massing models could be built quickly and at any point in the project. Three-dimensional visualization allows design to proceed in real world coordinates and at any angle, something respondents report helps improve their designs. Finally, the respondents felt that it helps to show their clients the design in 3D, which can be helpful because many clients cannot visualize a building from 2D drawings. A 3D image improves the quality of the design by letting the client see the actual building, simplifying the task of specifying needed changes.

There are many other ways that design automation can improve design quality. Most respondents indicated that a computer helped them present their ideas better. Other respondents felt that automation helped improve the quality and quantity of services available from the Corps of Engineers. Still other respondents felt that complex designs were easier to complete with automation. Finally, the majority of the respondents indicated that automation provides a consistency among the disciplines that helped improve their designs.

\section{Quality Documents}

Design automation helps produce drawings and other construction documents in a more professional manner than pencil-and-paper drafting. Drawings done on a computer are free from eraser smudges, and line weights and styles are consistent. Graphic layouts of drawings are done more efficiently on a computer and look more professional when complete. These factors combine to make the drawings easier to read and to enhance their professional appearance. Most respondents expressed the opinion that automation increased the clarity and professional appearance of construction documents.

Design automation improves construction documentation by improving its accuracy. Borders, details, and symbols can all be stored in commonly accessible electronic libraries so that all drawings use standardized elements. Most respondents to the present survey stated that design automation made it easier to implement drawing standards, and that when implemented, the standards improved the quality of the drawings. Other survey respondents indicated that auto-dimensioning also helped to improve the accuracy of a drawing. Auto-dimensioning removes human error from measurements, and provides clean, easy-to-read dimensions. The third way to achieve better quality and more accurate construction documents is to have a better design-checking system. Most respondents expressed the opinion that automation had helped make design checking a thorough process. 
A study of a computerized database of professional liability cases for about 5000 buildings and 2500 civil works dating from 1980 to 1987 determined the common reasons for construction failure disputes ("Failure Causes Studied" 1991). Construction failures were defined as "the results of the unfulfillment of a claim, promise, request, need or expectation between the design professional and client."

The study found that site work, roadways, and equipment are the biggest problem areas for the civil area (Figure 12). "In buildings, design service problems were the biggest factor in the incidents studied, overshadowing construction services, specifications, nonpayment of fees and inspections."

The U.S. Army Corps of Engineers (USACE) requires review procedures for technical design and Biddability, Constructibility, and Operability (BCO), as well as functional reviews conducted by the end users during the design phase, to aid in detecting omissions, ambiguities, and inadequacies in the design, therefore reducing possible disputes (Kirby 1988).

"The automated process does not change the likelihood of an error in content. If a person was going to make a mistake before, the potential is there that he is going to make that mistake now" (Hoyte 1989, p 60). To date, very few claims have appeared claiming negligence due to or resulting from the use of CADD or automation. However, the use of automation may, if not monitored properly, expose the professional to new and different types of liabilities (Gough 1989).

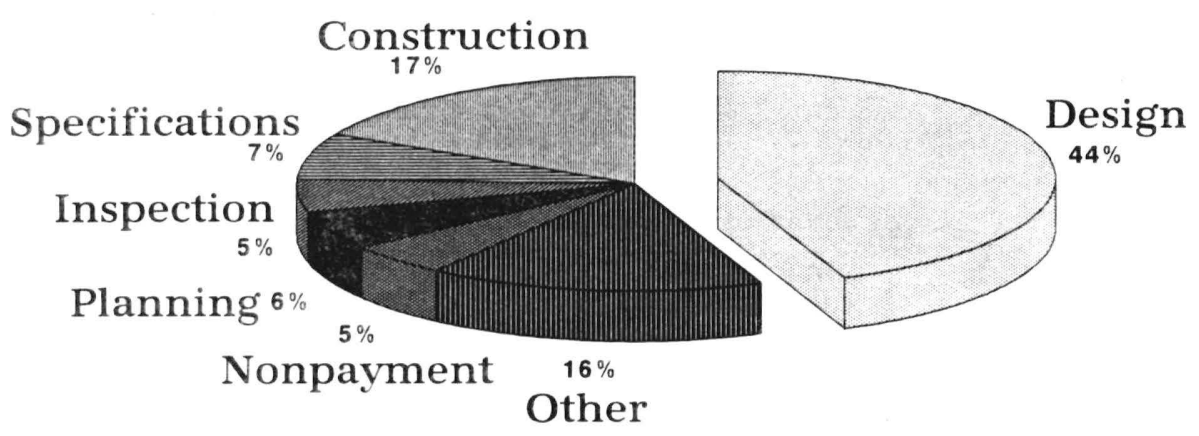

Source: AEPIC

Figure 12. Reasons for Disputes Involving CADD. 


\section{Misconceptions About CADD}

The evolution of computer software programs was accompanied by client and user misconceptions about the acquisition, use, and reliability of these programs. One of the first misconceptions is that "CAD" still means Computer Aided Drawing (as it did a decade ago). Today "CADD," or Computer Assisted/Aided Drafting and Design is not only a powerful drafting tool, but a design, data management, and decisionmaking tool.

Some clients believe that, since CADD can make easy, fast, and inexpensive changes to drawings, that it can also incorporate those changes right up to bidding. "Machines and software are only as capable as the operators, with each having its own strengths and limitations" (Kennedy 1988). Modifications to CADD drawings do take time to coordinate, resource, and implement. Misunderstanding this simple fact may lead to costly errors.

Some users believe that off-the-shelf software is error-free, and that artificial intelligence embedded in the software can make the same rational judgments as a design professional. Here again, without constant monitoring, errors due to software or misuse of software may arise

Not until clients and design professionals understand the potential of CADD without unrealistic expectations will the risk of legal liability disappear. "CADD is not a magic solution but can, if properly used, make the design professional's services easier and more profitable to perform. If CADD is not respected as only a valuable tool, but rather is relied upon as a crutch or substitute for judgment, potential for legal liability will surely follow" (Gough 1989).

\section{Transfer of CADD Data}

The Corps has standardized on the Intergraph environment and often requires the A/E to deliver documents in Intergraph-native format (DGN). The Naval Facilities Engineering Command (NAVFAC) has a large base of Computervision ${ }^{\circledR}$ equipment and software and requires compatibility. The Navy mostly requires AutoCAD® and the National Park Service uses Auto-trol ${ }^{\circledR}$ systems. For the most part, corporate and private architectural and engineering firms use Autodesk. ${ }^{\circledR}$ Failing to negotiate who is responsible for costs and quality control of transferring CADD data when different CADD systems are used, can lead to unanticipated problems (Fallon 1988).

There must be an understanding of what is involved in achieving compatibility. Compatibility can be broken into different equivalences (Fallon 1988a). Visual equivalence is where all graphics information is transferred and the plotted drawings look identical. Functional equivalence is much like visual equivalence, but the data can be manipulated in the receiving system as if it had been created there. Attribute equivalence is the transfer of nongraphic, as well as graphic data, to the receiving system. Lastly, Data organization equivalence is where the client requires their CADD data standards for the project. This may involve standard line weights, fonts, text styles, symbols and title block.

The contract should specify exactly what will be translated and delivered. It is imperative to determine the extraneous files that will be necessary (drawing, cell, reference, block, specifications, database, text), the medium the data should be stored on (5-1/4-in. floppy, 3-1/2-in. floppy, tape, compact disk), and the required drawing standards (levels, scales, symbols, abbreviations, drawing elements). Unless the same CADD system and application software are used, exact translations of drawings and drawing attributes are rarely possible. Both the client and design professional should be aware of this and should plan accordingly. 
Another legal issue arises with the transfer of CADD data to the client. Certain precautions should be made to protect the integrity of the CADD data. In the past, changes to mylar or vellum drawings would be apparent, but with the use of automation, modifications and misuse of CADD data is undetectable. The contract should specify who has permission to modify or initiate modifications to the CADD data. For documentation purposes, the original CADD data or documents should be retained by the design professional.

\section{Getting Paid for CADD}

The misconception that CADD is faster, easier, and cheaper than manual drafting leads clients to believe that services rendered using CADD will cost less. Generally, this is not true. Getting clients to pay for CADD has been a major problem for firms. Many firms fail to separate and examine the costs associated with using CADD. Unforseen expenses such as maintenance, training, and overhead may arise, reducing the firms profit. The concern is that the firm may try to recover these costs by reducing the quality of service and of the project.

The PSMJ survey found that 40 percent of the firms do not separately account for CADD costs; they simply treat this expense as part of overhead. The firms are only able to bill 35 percent of their projects on CADD use, which is only half of the projects CADD is used on. The current median billing rate is $\$ 25$ per hour, not including the cost of the CADD operator. Previously, system type was a factor in billing rates. This no longer appears to be true. The $\$ 25$-per-hour rate seems to be a market value rather than a cost-based value, including a median target profit of 15 percent.

The same survey showed that:

Even though government sector clients have proclaimed to be ardent supporters of CADD, they are less likely to pay for CADD costs. When they do pay, it is at a lower rate than private sector clients. This lower compensation is ironic since several major government agencies have adopted policies standardizing their requirements on higher cost CADD systems.

\section{Training}

Formal training on today's complex CADD systems has become a necessity. Rapid changes in CADD software demand continually updated training. Without this training, users would be unable to become efficient and productive, or to take full advantage of the CADD system capabilities. Training by experienced instructors decreases learning time by as much as half and does not tie up workstations or experienced CADD staff (Kennedy 1988).

The PSMJ survey shows that the median time required for training CADD operators is 10 days. This has remained constant for the past 3 years. This survey also found that training time is somewhat higher for firms with multiple types of CADD systems than for firms with only PC-based systems. "The longer the training, the more likely a firm will use advanced CADD capabilities. Use of these advanced capabilities results in higher productivity. Thus additional training appears to be justified" (Practice Management Associates 1991).

Computer-aided instruction has been a subject of research at the U.S. Army Construction Engineering Research Laboratories for several years. Studies have shown that the majority of those participating in the instruction sets felt that the time spent on the lessons was not lost (Shaw 1989, 1990). Ninety-eight percent of those participating also indicated that they would like to see more computer-aided 
training made available. Others indicated that they liked computer-aided training and learned more quickly from the computer than from textbooks.

The research also revealed many aspects of the instruction sets that need to be modified. The trainees felt training should be done while working and as closely related to the work being done as possible. Other trainees expressed the need to be able to reference commands quickly with as little interruption as possible. The graphics were appreciated, but the users felt that graphics would be more useful if they were linked to the learning objectives. Finally, users felt that the lessons should be controlled by the user with assistance from the computer only upon demand.

\section{Updates}

Frequent software and hardware updates make many old CADD drawings obsolete by current drawing standards. Older CADD packages, for the most part, lacked uniformity, coordination between layers and disciplines, automatic dimensioning, 3D capability, and database links. When a firm needs to change files created with old CADD programs, care must be taken to ensure enough time to translate and modify into the new format. Data translation is a much larger job than most firms schedule and bill for.

Industry efforts and software updates may resolve some of these concerns, but "uncoordinated CADD programs can result in considerable confusion. Confusion, of course, fosters mistakes and misunderstandings which, in turn, often translate into a liability problem for the design professional" (Gough 1989).

\section{CADD Management and Support}

Maintaining CADD user effectiveness, software, hardware, and drawing standards has turned into more than a full-time job. "When we moved from hand drawing into CAD, we tried to manage our projects pretty much as we always had and it doesn't work. You must learn new techniques to go along with the new technology. If you do learn, you will greatly reduce the likelihood of problems" (Hoyte 1989).

A design professional involved in a project often has little time to manage and stay abreast of the new technologies. CADD systems have become too complex to expect the CADD user to be selfsupporting. This is not an efficient use of a CADD user's time, and "it does not lead to an efficient solution, even when it works. One of the things that is needed is an integrated global system of fixing, maintaining, organizing and supporting the CADD system" (Sankey 1991).

A partial list of issues concerning CADD support was generated by architects from Kansas City District (CEMRK-ED-DA) and discussed at the Architectural Automation Task Group meeting held 19-20 September 1991. These expressed user needs should be addressed by CADD support:

1. All workstations need to have the same setup and logon procedure. (Assume nondedicated workstations.)

2. All cell libraries need to be on all workstations.

3. All menus (paper, screen, keyboard) need to be set up on all workstations. 
4. Users should be able to plot to either the laser plotter in the Design Branch CADD room or any of the plotters in the Drafting Branch from any of the workstations.

5. All workstations should be updated to the latest software. Updates need to done all at once (over a weekend). All supporting files need to be installed at the same time.

6. Whenever possible, all support should be done without interfering with production work.

7. Updates must be done correctly and be complete. Questions about updates and debugging, etc., need to be done by the CADD support (not left to the user to resolve).

8. Corps needs a workable plan in place for transitioning from VAX to workstations.

9. Corps needs a workable plan in place for storing and accessing project drawings.

10. Users need to be able to back up all drawing files from the workstations.

11. A drawing file checkout system needs to be in place. Checkout system must prohibit simultaneous work on a drawing file from multiple workstations.

12. Districts need to be able to upgrade without losing any ... completed customization of software.

13. Districts need someone to do customization of both system and application software to ... “group” needs.

14. Districts need a log-on bulletin board that informs users of any system activity that will affect their use of the system.

15. Districts need someone who can take time to answer any questions.

16. Districts need to support users during all worktime, even after normal office hours or on weekends.

In the Corps, not all design and drafting branches are supported in the same manner. In some instances Information Management (IM) supports everyone. In other cases, individual branches have their own support.

In Kansas City's case, one recommended solution would consist of hiring one full-time person, not many part-time people, to work full-time exclusively for the drafting branch. In addition to this full-time government position, one professional CADD support person from the private sector should also be hired. This person would be hired by and work for the drafting branch.

The timely production of design and construction documents is of vital importance to accomplish the mission of the Corps of Engineers' design and drafting branches. Whatever the solution, there is obviously "a need for continuous, enthusiastic CADD support" (Sankey 1991). 


\section{SUMMARY}

This phase of research collected information from various sources on the status and use of CADD software as a design automation tool: current and past automation surveys, CADD liability cases, design reviews, and compilations of design errors and modifications. The American Institute of Architects (AIA) was also contacted for information on design liability and errors that may result from automation.

Most surveyed firms that use computers for design automation stated that they intended to expand their systems' hardware during the year of the survey. Most computer users had good access to their equipment, and stated that they used computers in their jobs most (78 percent) of their work day. At the time of this study, total software sales had fallen off from previous years. Fewer firms were making (or planned to make) software purchases, although individual purchases tended to be larger. In general, A/E firms spend about 5 to 7 percent of their overhead on software, although larger firms budgeted more than small firms for software purchases.

A/E firms are generally quick to accept forms of automation like CADD that are economical and easy to implement. Problems associated with hardware and software support can make A/E firms hesitant to expand or upgrade their hardware and software options, or to use available systems to their full capabilities. A/E firms presently use only a small amount of the software available to automate their daily tasks. The most popular programs in general use are: drafting, detailing, scheduling, design, and word processing. There is still a need for new or improved software to perform: estimating, job cost, accounting, and scheduling.

A survey of $\mathrm{A} / \mathrm{E}$ firms revealed that CADD training translated into higher pay for nonprofessional (technicians and draftsmen) than for professional employees (architects and engineers).

Most surveyed A/E firms expressed the belief that automation has improved design firm productivity. However, such productivity gains are not instantaneous; it generally takes time to learn the automated technology before realizing gains in productivity and profitability. Large architectural and design firms (over 300 employees) express a greater confidence that their CADD investments will realize significant gains in productivity and profitability.

Most survey respondents noted that design software allowed them to concentrate on design alternatives, which contributed positively to the quality of their design documents. Moreover, 3D imaging was seen to improve both quality and quantity of design work, and to make presentations of designs more accessible to clients.

Often, complaints about CADD software are related to misconceptions about the software's capabilities. No automated process, for instance, can change the likelihood that an error in content may occur. It is naive to believe that changes to design drawings, that are greatly simplified by using CADD, are instantly incorporated into the whole design process, right up to bidding. Similarly, artificial intelligence embedded in software can help, but not replace, the experienced judgments of the design professional.

Another common misconception is that, since drafting with CADD is faster, cheaper, and easier than manual drafting, services rendered with the software should be correspondingly less expensive. This is not always true, and it is important for A/E firms to consider the costs of maintenance, training, and overhead that accompany the use of design automation software. 
It is imperative that CADD users coordinate their systems and applications between client and design professional. Care should be taken to preserve the integrity of CADD data since alterations to electronic data are transparent to the viewer.

The second phase of this research will review and analyze reports from the Automated Review Management System (ARMS) and the Construction Evaluation Retrieval System (CERS) to determine how automation has affected Corps review procedures, and to locate and classify repetitive data that may be streamlined in future designs and construction projects.

\section{REFERENCES}

East, E. William, Opportunities for Design Quality Improvement Through Architect/Engineer (A/E) Liability Management, Technical Report (TR) P-88/13/ADA197832 (U.S. Army Construction Engineering Research Laboratory [USACERL], September 1988).

“Failure Causes Studied,” Engineering News Record (15 July 1991).

Fallon, Kristine K., “CADD Deliverables,” Architectural \& Engineering Systems (October 1988a), pp 44-49.

Fallon, Kristine K., “The Organizational Learning Curve,” Computer Applications in Engineering, Planning, and Architecture (CEPA) Proceedings (1988b).

Faulkner, E., "Computer Use in the Construction Industry," Constructor (December 1988), pp 35-36.

Gough, Gary C., “CADD Liability Implications,” Guidelines for Improving Practice, Vol XIX, No. 2 (1989).

Hoyte, Charles K., “An Expert Panel Explores the Pros and Cons of Computerized Specifications," Architectural Record (June 1989), pp 159-165.

Hoyte, Charles K., “An Expert Panel Explores the Pros and Cons of Computerized Specifications: Part II, Architectural Record (August 1989), pp 131-136.

Kennedy, Lee, “Computers: 13 Myths of CAD,” Progressive Architecture (October 1988), pp 51-53.

Lawrie, Linda K., William P. Bahnfleth, and Jeffrey D. Morton, Surveys of Architectural, Electrical, and Mechanical Hardware/Software Use and Needs, Special Report (SR) E-90/02/ADB141117 (USACERL, January 1990).

Peltz, Curtis, "The Movement Toward Computer-Integrated Construction," The Construction Specifier (June 1989), pp 73-75.

PSMJ CADD Application and User Survey Exclusively for Design Firms (Practice Management Associates, Ltd., July 1991).

Sankey, John, “An Attempt at Organizing Our Thoughts on the Support of Our CADD," Minutes/Proceedings: Architectural Automation Task Group Meeting (19-20 September 1991), ARC-M-1 (October 1991), attachment J.

Shaw, D.S., L.M. Golish, and R.L. Johnson, Intelligent Embedded Instruction for Computer-Aided Design (CAD) Systems, TR P-89/03/ADA201811 (USACERL, October 1988).

Shaw, D.S., and L.M. Golish, Followup Studies on Embedded Instruction for CAD Systems, TR P-90/10/ADA222509 (USACERL, May 1990).

Thomas, G. Lane, "Information Systems: The Future of the A/E Industry Will Be Shaped by How Designers Come to Terms With Today's Emerging Information Technology," The Construction Specifier, Vol 40 (April 1987), pp 54-61.

Wohlers, Terry, “CAD '88," Architectural \& Engineering Systems, Vol 3 (January 1988), pp 20-27. 


\section{APPENDIX A: Example Survey}

\section{SURVEY OF DESIGN AUTOMATION IN THE U.S. ARMY CORPS OF ENGINEERS}

Please complete this survey about your computer-related work. Return to: Beth Symonds@FSA, P.O. Box 9005, Champaign IL 61826-9005.

Question: How has computer automation affected your work in Architecture and Engineering for the Corps of Engineers?

GENERAL QUESTIONS:

Name (optional):

Discipline/Training:

Office Symbol:

G.S. Grade Level (optional):

Position Title:

Manager/Supervisor for (number of people):

1. I use a computer for:

Drafting

Yes No Software Used Specification writing

Word processing

Engineering calculations

Design modifications

Presentation graphics

Lighting design

HVAC design

Electrical design

Mechanical design

Code analysis

Electronic catalogs

Training

Quantity take-offs

Planning

Scheduling/Time mgmt.

Budgeting/Cost estimating

Resource mgmt.

Design review

Communication (E-mail)

Interference checking

Space planning

Interior design

Solid modeling

Facility management

Database archiving

2. What type of computers do you have access to (i.e. mainframes, work stations, or personal computers)?

$\begin{array}{llll}\text { Mainframes } & \text { Yes } & \text { No } & \text { percent of time used } \\ \text { Personal computers } & \text { Yes } & \text { No } & \text { percent of time used } \\ \text { Work stations } & \text { Yes } & \text { No } & \text { percent of time used }\end{array}$

3. Name the tasks in your office that could be optimized by automated applications. Which applications?

4. Name the tasks in your office that you would LEAST like to automate. Why?

5. Which daily task or function do you complete MOST successfully on the computer? Why?

6. Do you feel the range of services provided by the Corps of Engineers have changed since the introduction of automation? If so, how? 
7. What percentage of your total work is done on the computer?

8. In your office, what is the ratio:

Number of people needing a computer $=$

Number of available computers

\section{PRODUCTIVITY}

Because of automation:

$$
\text { Disagree Agree N/A }
$$

Time spent updating drawings or documents is increased.

Doing repetitive tasks is easier. Less time is needed to create quality drawings.

More time is needed to complete final drawings.

More design alternatives are possible in less time.

There is a better finished product in less time.

Drawing modifications take more time.

Final production of drawings is more complex.

Archived data and drawings are more accessible.

Fewer resources are required to complete a project.

There is a decrease in design productivity.

Schematic designs can be developed

in less time.

Standard detail libraries make

drawing production easier.

\begin{tabular}{|c|c|c|c|}
\hline 1 & 2 & 3 & 4 \\
\hline 1 & 2 & 3 & 4 \\
\hline 1 & 2 & 3 & 4 \\
\hline 1 & 2 & 3 & 4 \\
\hline 1 & 2 & 3 & 4 \\
\hline 1 & 2 & 3 & 4 \\
\hline 1 & 2 & 3 & 4 \\
\hline 1 & 2 & 3 & 4 \\
\hline 1 & 2 & 3 & 4 \\
\hline 1 & 2 & 3 & 4 \\
\hline 1 & 2 & 3 & 4 \\
\hline 1 & 2 & 3 & 4 \\
\hline 1 & 2 & 3 & 4 \\
\hline
\end{tabular}

1. What tasks take less time when done on the computer?

2. To what extent does computer drafting save time or add time compared to manual drafting?

3. Has automation improved your productivity. If so, how?

4. Has the use of computers decreased the time spent on design projects? If so, by approximately what percent? How is the saved time used?

5. By approximately what percentage has the use of a computer decreased the time spent doing repetitive tasks?

6. What percentage of your tasks are performed on a computer?

\section{COMMUNICATION}

Because of automation:

$$
\text { Disagree Agree N/A }
$$

Graphically communicating ideas and data is easier.

Coordinating work done by all of the project members is easier.

$\begin{array}{llll}1 & 2 & 3 & 4 \\ 1 & 2 & 3 & 4\end{array}$


Monitoring the progress of a project is easier. Accessing drawings is harder. Workers are better informed of changes in the project.

More people are able to work together on a project.

Coordination between disciplines is harder.

$\begin{array}{llll}1 & 2 & 3 & 4\end{array}$

$\begin{array}{llll}1 & 2 & 3 & 4\end{array}$

$\begin{array}{llll}1 & 2 & 3 & 4\end{array}$

$\begin{array}{llll}1 & 2 & 3 & 4\end{array}$

Communicating with consultants is

easier.

$\begin{array}{llll}1 & 2 & 3 & 4\end{array}$

Providing data and drawings for

clients and contractors is easier.

Contract modifications are harder.

$\begin{array}{llll}1 & 2 & 3 & 4\end{array}$

1. Has automation helped you present designs more clearly? If so, how?

2. In what ways has automation facilitated communication between parties involved with the project?

3. Are fewer drawing modifications required because of the ability to communicate with all disciplines? If so what percentage? 


\section{QUALITY}

Because of automation: Disagree Agree N/A

Generating different design possibilities takes less time.

Designs have improved.

Drawing standards are more

difficult to implement.

Checking a drawing has become a

more thorough process.

I am better able to present my

ideas.

Fewer drawing corrections are required.

Final documents and drawings have

a more professional appearance.

Standards are implemented more accurately.

My ability to express my design ideas is hindered.

Drawings are better coordinated.

Drawings and documents are more difficult to read.

Human error is less of a concern

in engineering calculations.

Projects are presented in a more

clear and more concise manner.

Less time is spent drafting more

time is spent on design aspects.

Services provided by the Corps of

Engineers are better quality.

$\begin{array}{llll}1 & 2 & 3 & 4\end{array}$

$\begin{array}{llll}1 & 2 & 3 & 4\end{array}$

$\begin{array}{llll}1 & 2 & 3 & 4\end{array}$

$\begin{array}{llll}1 & 2 & 3 & 4\end{array}$

$\begin{array}{llll}1 & 2 & 3 & 4\end{array}$

$\begin{array}{llll}1 & 2 & 3 & 4\end{array}$

$\begin{array}{llll}1 & 2 & 3 & 4\end{array}$

Quickly developing design

alternatives permits the ability

to make better design decisions.

Drawing layouts have improved.

Complex designs are harder to

complete.

$\begin{array}{llll}1 & 2 & 3 & 4\end{array}$

$\begin{array}{llll}1 & 2 & 3 & 4\end{array}$

$\begin{array}{llll}1 & 2 & 3 & 4\end{array}$

$\begin{array}{llll}1 & 2 & 3 & 4\end{array}$

$\begin{array}{llll}1 & 2 & 3 & 4\end{array}$

$\begin{array}{llll}1 & 2 & 3 & 4\end{array}$

$\begin{array}{llll}1 & 2 & 3 & 4\end{array}$

$\begin{array}{llll}1 & 2 & 3 & 4\end{array}$

1. How does automation improve the quality of the final design and drawings?

2. When using computers in the design process, does the ability to quickly develop alternatives affect the way you design? If so, how?

3. Describe how solid modeling (3D viewing ) helps or hinders the design process?

Automated drafting
time spent drafting? __ percent on design? __ percent
Manual drafting
time spent drafting? _— percent on design? _— percent




\section{APPENDIX B: Numeric Survey Results}

\section{SURVEY OF DESIGN AUTOMATION IN THE U.S. ARMY CORPS OF ENGINEERS}

Please complete this survey about your computer-related work. Return to: Beth Symonds@FSA, P.O. Box 9005, Champaign IL 61826-9005.

Question: How has computer automation affected your work in Architecture and Engineering for the Corps of Engineers?

\section{GENERAL QUESTIONS:}

Name (optional): 13 surveys completed

Discipline/Training:

Office Symbol:

G.S. Grade Level (optional):

Position Title: 10 architects and 2 interior designers

Manager/Supervisor for (number of people): 2 managers

I use a computer for:

\begin{tabular}{|c|c|c|c|}
\hline & Yes & No & Software Used \\
\hline Specification writing & 12 & 1 & Wordperfect \\
\hline Drafting & 13 & $\mathbf{0}$ & AutoCad/Ustn \\
\hline Word processing & 13 & $\mathbf{0}$ & Word Perfect \\
\hline Engineering calculations & 3 & 10 & Lotus/STAAD III \\
\hline Design modifications & 11 & 2 & AutoCad/Ustn \\
\hline Presentation graphics & 9 & 4 & AutoCad \\
\hline Lighting design & 1 & 12 & AutoCad \\
\hline HVAC design & $\mathbf{0}$ & 13 & None \\
\hline Electrical design & 2 & 11 & AutoCad/CAPACAD \\
\hline Mechanical design & $\mathbf{0}$ & 13 & None \\
\hline Code analysis & 2 & 11 & Plan Analysts \\
\hline Electronic catalogs & 3 & 10 & Sweets/CAPACAD \\
\hline Training & 3 & 10 & Parch/Ustn \\
\hline Quantity take-offs & 5 & 8 & AutoCad/CAPACAD \\
\hline Planning & 3 & 10 & AutoCad/CAPACAD \\
\hline Scheduling/Time mgmt. & 5 & 8 & Enable \\
\hline Budgeting/Cost estimating & 7 & 6 & Enable \\
\hline Resource mgmt. & $\mathbf{0}$ & 13 & None \\
\hline Design review & 6 & 7 & ARMS \\
\hline Communication (E-mail) & 8 & 5 & Banyan \\
\hline Interference checking & 5 & 8 & AutoCad/Ustn \\
\hline Space planning & 7 & 6 & AutoCad/CAPACAD \\
\hline Interior design & 8 & 5 & AutoCad/Ustn \\
\hline Solid modeling & 5 & 8 & AutoCad \\
\hline Facility management & 1 & 12 & IGDS \\
\hline Database archiving & 1 & 12 & PKARK \\
\hline
\end{tabular}

1. What type of computers do you have access to (i.e. mainframes, work stations, or personal computers)?

$\begin{array}{llllll}\text { Mainframes } & \text { Yes } \mathbf{4} & \text { No } & \mathbf{9} & \text { percent of time used } & \mathbf{3 . 3} \\ \text { Personal computers } & \text { Yes } \mathbf{1 3} & \text { No } & \mathbf{0} & \text { percent of time used } & \mathbf{7 7 . 8} \\ \text { Work stations } & \text { Yes } \mathbf{9} & \text { No } & \mathbf{4} & \text { percent of time used } & \mathbf{1 5 . 4}\end{array}$

2. Name the tasks in your office that could be optimized by automated applications. Which applications?

$\begin{array}{ll}3 & \text { detailing } \\ 1 & \text { repetitive tasks } \\ 2 & \text { drafting }\end{array}$ 


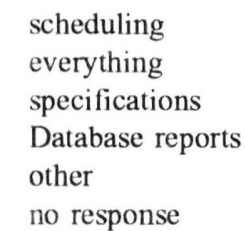

\section{Comments:}

- Details for construction documents.

- Details for construction documents need to be cataloged and accessible by personal computers.

- Everything needs to be automated.

- Optimize design and drafting of plans.

- Word processing, forms, design documents, rep

- Scheduling, project management

- Drafting because some non-CADD oriented designers develop designs and details to a great degree only to have someone else input the data into the computer

- Data base reports, standard class codes, P-Arch

- Time/money spent on projects

- Being able to access SpecNet on any workstation- so the I would not have to go find available PC to produce specs.

- Detailing, reports, schedules, quantities, keynoting, sheet organization, vertex, construction documents.

- I am sure there are more - I am not thinking of any right now. I think I just want to get proficient on the computer applications I have available.

3. Name the tasks in your office that you would LEAST like to automate. Why?

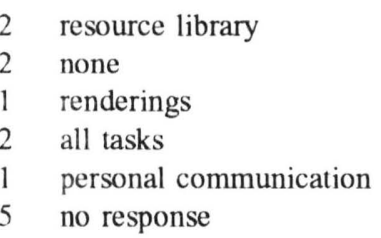

\section{Comments:}

- Resource library, finish selection, difficult to be done by automation. Ex. electronic sweets, not utilized

- Filing resource library, finish research and selections- I don't know that it can be successfully done. We need to use the real thing.

- Renderings, color presentation work

- I would like to see as many tasks as possible automated in my office

- Personal communication- some where in the design process the human touch is still needed

- All need automation

4. Which daily task or function do you complete MOST successfully on the computer? Why?

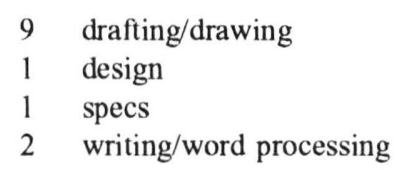

\section{Comments:}

- Architectural drafting

- There really are no "daily" tasks - in terms of project production- drafting is the most successful

- Drawings, because of the accuracy of the drawings created plus CAPACAD gives us capability to do cost take-offs for systems furniture

- Drafting attributing parts pieces, components, furniture. Accuracy and reproduction capabilities at various scales.

- Drafting, word processing, spread sheet

- Drafting is the most successful task on the computer because of the ease of revisions and modifications

- Specification- familiarity with the software package (it hasn't changed a lot recently)

- Word processing. Using an out-liner (pc-outline) Design review comments DO LIST, random thoughts on various bits and pieces of multitude of things daily. 
- Design makes work seem easier- clearer- more efficient

- Construction drawings, adequate training and hardware

- Writing, allows much or increased flexibility freedom, error correction. Allows mind to work without getting sidetracked on spelling or organization or grammar.

5. Do you feel the range of services provided by the Corps of Engineers have changed since the introduction of automation? If so, how?

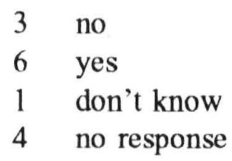

\section{Comments:}

- No, in the 3 years I have been here I have seen no change in service to the client or any reduction in design schedules due to automation.

- More varied presentations, i.e., animation, perspectives are now included in 10 percent

- The Corps was fairly automated previous to my employment

- Yes, able to exchange information electronically with $\mathrm{A} / \mathrm{E}$

- I feel the range of services are still about the some but automation of some of those services has allowed the Corps of Engineers to take a different approach in providing some of those services

- Yes- presentation capabilities

- Yes- Just by the vast amount of resources in place and commitment by the Corps

- I don't think the range has broadened much yet we should be able to offer modeling capabilities and support facility management needs.

\section{What percentage of your total work is done on the computer?}

$$
74 \text { percent }
$$

7. In your office, what is the ratio:

Number of people needing a computer $=\mathbf{0 . 6 4 2 5}$

Number of available computers

\section{PRODUCTIVITY}

Because of automation:

$$
\text { Disagree Agree AVG. }
$$

Time spent updating drawings or documents is increased.

Doing repetitive tasks is easier. Less time is needed to create quality drawings.

More time is needed to complete

final drawings.

More design alternatives are possible in less time.

There is a better finished product in less time.

Drawing modifications take more time.

Final production of drawings is more complex.

Archived data and drawings are more accessible.

Fewer resources are required to complete a project.

$\begin{array}{lllll}1 & 2 & 3 & 4 & \mathbf{2 . 1 9} \\ 1 & 2 & 3 & 4 & \mathbf{3 . 8 5} \\ 1 & 2 & 3 & 4 & \mathbf{2 . 8 0} \\ 1 & 2 & 3 & 4 & \mathbf{1 . 7 0} \\ 1 & 2 & 3 & 4 & \mathbf{2 . 7 0} \\ 1 & 2 & 3 & 4 & \mathbf{3 . 0 0} \\ 1 & 2 & 3 & 4 & \mathbf{1 . 5 0} \\ 1 & 2 & 3 & 4 & \mathbf{1 . 7 0} \\ 1 & 2 & 3 & 4 & \mathbf{2 . 7 0} \\ 1 & 2 & 3 & 4 & \mathbf{2 . 2 0}\end{array}$


There is a decrease in design productivity.

1

Schematic designs can be developed

in less time.

Standard detail libraries make

drawing production easier.

$\begin{array}{lll}2 & 3 & 4\end{array}$

$\begin{array}{llll}1 & 2 & 3 & 4\end{array}$

$\begin{array}{llll}1 & 2 & 3 & 4\end{array}$
1.80

2.10

3.30

1. What tasks take less time when done on the computer?

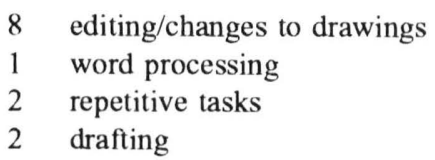

Comments:

- $\quad$ Editing and modifying drawings

- Changes to drawings, editing

- Changes to flood plans

- Modifying a design after user changes

- Word processing as compared to typing

- Typical furniture/workstation layouts, reproduction of specific areas/rooms at different scales, quantity take-offs, cost estimates for workstations

- Drafting, revising drawings

- Tasks in which repetitive items can be utilized or items which have been created for previous job can be incorporated.

- Creating large scale plans from a small scale plan or visa versa

- Changes to drawings

- Repetitive work- creating reflective ceiling plans, roof plans, enlarged plans

- Drawing revisions, drawings with common elements, repetitive drafting, 3-D visualization.

- Making changes (drawing/writing/estimates) What tasks take more time on computer. (Initial draft of simple sketch drawings)

2. To what extent does computer drafting save time or add time compared to manual drafting?

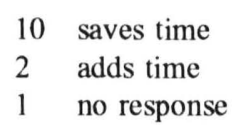

\section{Comments:}

- $\quad$ Saves time when repetitive

- With the computer you can not see the drawing e.g., floor plan as a whole thus requiring constant referral to a full size drawing on paper and continual zoom-in or zoom-out

- New complex details require more time

- "Referenced" drawing changes can update several sheets in one correction

- Saves time of duplicating building shell (from architect) and duct work (mechanical) and under floor raceways (electrical) just for example

- In the initial stages CAD adds time, in middle stages and final design it saves time.

- Computer saves time esp. when repetitive

- More time may be required when a unique or once used design is used because of the precise input data required, a much greater time savings can be realized if repetitive item are used or a design is used more than once

- Computer drafting at present takes more designer time but it ultimately saves time because it eliminates the middle man and a large number of error which are ultimately created when more then one person works on a project.

- To the very extreme - i.e,. When you update an item on the title block all 50 or so sheets are updated in entire set. You can see the savings. (This is just a small example.)

- See above for saving time, additional time is required to set up data base for floor plan

- Save time on changes and final clean up. Adds time on set up and initial versions of drawings. 
3. Has automation improved your productivity. If so, how?

$$
\begin{aligned}
& \text { yes } \\
& \text { no } \\
& \text { same }
\end{aligned}
$$

Comments:

- No, but if data based libraries where available it would make productivity increase

- No, but I feel it cold if we had data base libraries set up to pull information and drawings from.

- As actual drawing production has increased greater detailing of a design is possible

- Yes, the increased speed for drafting

- Yes, reproduction of drawings at various scales and or with various information related to the design document building shell and other information is shared electronically. Also word processing is faster.

- More accurate readable consistent work

- Yes, especially if a design is used more than once and as standard details are created and stored to be used over again.

- No, but once full change over has been made by all disciplines and the support staff (techs.) are up to speed and familiar with arch. format and procedures productivity should be increased.

- Yes, one can easily use add jobs as models for new ones and easily adopt

- Yes, being able to make deadlines by improving on quality of work- you can not cheat when you are drawing on CADD

- Yes, less duplication is performed by utilizing reference files, copying details and symbols

- Yes, My end product is better, nicer looking, and better organized - sometimes quicker

4. Has the use of computers decreased the time spent on design projects? If so, by approximately what percent? How is the saved time used?

$\begin{array}{ll}7 & \text { no } \\ 5 & \text { yes } \\ 1 & \text { N/A }\end{array}$

\section{Comments:}

- No, I personally find them impractical during design due to the limiting size of the screen to be able to see the whole design

- Time has not decreased because more effort now goes into building design and final detailing

- Overall yes., by 15-20 percent. Time is not viewed as "saved time." We estimate our time on our production capabilities incl.CAD etc.

- Decreased by 15 percent. Time used to manage project/ other disciplines

- Design time has found to be decreased mostly on common projects or jobs in which details from previous jobs may be used

- Yes, I think for 50 percent the time saved is needed, however to keep up with the changing technology

- No, saved time is used on spending more time on the quality of details- more design time/ and a more thorough project

- Yes, 25 percent avg. Able to take on more projects and spend more time doing thorough reviews

- No, it has taken me a long time to build competence. Next year I will be able to answer yes.

5. By approximately what percentage has the use of a computer decreased the time spent doing repetitive tasks?

\section{What percentage of your tasks are performed on a computer?}

45.5 percent

\section{COMMUNICATION}

Because of automation:

\section{Disagree Agree}

Graphically communicating ideas

and data is easier.

Coordinating work done by all of

the project members is easier.

Monitoring the progress of a

project is easier.

Accessing drawings is harder. $\begin{array}{llll}1 & 2 & 3 & 4\end{array}$

$1 \quad 2 \quad 3 \quad 4$

$\begin{array}{lll}2 & 3 & 4\end{array}$

234

AVG. 
Workers are better informed of changes in the project.

More people are able to work together on a project.

$\begin{array}{llll}1 & 2 & 3 & 4\end{array}$

$\begin{array}{llll}1 & 2 & 3 & 4\end{array}$

$\begin{array}{llll}1 & 2 & 3 & 4\end{array}$

is harder.

Communicating with consultants is

easier.

Providing data and drawings for

clients and contractors is easier.

Contract modifications are harder. $\begin{array}{llll}1 & 2 & 3 & 4\end{array}$

$\begin{array}{llll}1 & 2 & 3 & 4\end{array}$

$\begin{array}{llll}1 & 2 & 3 & 4\end{array}$
3.10

2.70

1.70

2.90

2.90

\section{Has automation helped you present designs more clearly? If so, how?}

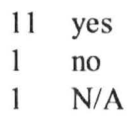

\section{Comments:}

- Yes, presentations can be enlarged for clarity

- Yes, cleaner drawings

- Numerous perspectives can be generated from a single computer model. Animated walk through of architectural designs are also now possible

- Yes, by the accuracy and clarity of drawings

- Yes, CAD produced drawings are clearer- lines better defined, symbols used do not change when shown in a multitude of places, I can show several options more easily

- Yes, can enlarge areas for presentations

- Yes, because to the precision required in the input of data there is a less likely chance of attempting to use the "fudge factor" which results in a much clearer presentation of a design

- Yes, precision input of data, graphic uniformity and clarity

- $\quad$ N/A do not use for presentations

- Yes, less thought needs to be placed on quality after you work out the various line weights

- Yes, graphics are more consistent and easier to read

- Yes, more flexibility in responding to user input

\section{In what ways has automation facilitated communication between parties involved with the project?}

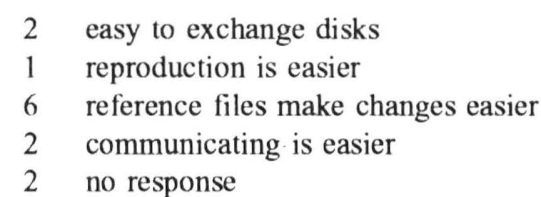

\section{Comments:}

- $\quad$ Easy to exchange disks

- Reproduction of current design drawings, from computer to hard copy

- Transfer of plans electronically reduces conflicts and number of errors

- Referenced drawings can be over-laid and checked for consistency and interference

- Drawings or portions there of can be shared among designers via electronic means with accuracy, can send/show clients options more easily

- $\quad$ Easy to exchange disks

- In using reference files there is easier and much better inter disciplinary coordination by allowing one discipline to overlay another disciplines drawings

- Quicker access to floor plan updates. This is done automatically and its instantly visible in all other files that the change is referenced to

- Automation within the project has lessened the burden of communication - automatic updating, warning flags go up when changes are made and system mail all contribute 
- Networking facilitates exchange of files and use of reference files

- Easier to get changes back in response to comments

3. Are fewer drawing modifications required because of the ability to communicate with all disciplines? If so what percentage?

45 percent

QUALITY

Because of automation:

\section{Disagree Agree}

Generating different design possibilities takes less time. Designs have improved.

Drawing standards are more difficult to implement.

Checking a drawing has become a more thorough process.

I am better able to present my ideas.

Fewer drawing corrections are required.

Final documents and drawings have a more professional appearance. Standards are implemented more accurately.

My ability to express my design ideas is hindered.

Drawings are better coordinated.

Drawings and documents are more difficult to read.

Human error is less of a concern

in engineering calculations.

Projects are presented in a more

clear and more concise manner.

Less time is spent drafting; more

time is spent on design aspects.

Services provided by the Corps of

Engineers are better quality.

Quickly developing design

alternatives permits the ability

to make better design decisions.

Drawing layouts have improved.

Complex designs are harder to complete.

\begin{tabular}{|c|c|c|c|c|}
\hline 1 & 2 & 3 & 4 & 2.70 \\
\hline 1 & 2 & 3 & 4 & 2.40 \\
\hline 1 & 2 & 3 & 4 & 1.80 \\
\hline I & 2 & 3 & 4 & 2.70 \\
\hline 1 & 2 & 3 & 4 & 2.90 \\
\hline 1 & 2 & 3 & 4 & 2.50 \\
\hline 1 & 2 & 3 & 4 & 3.80 \\
\hline 1 & 2 & 3 & 4 & 3.00 \\
\hline 1 & 2 & 3 & 4 & 2.20 \\
\hline 1 & 2 & 3 & 4 & 3.00 \\
\hline 1 & 2 & 3 & 4 & 1.10 \\
\hline 1 & 2 & 3 & 4 & 2.10 \\
\hline 1 & 2 & 3 & 4 & 3.30 \\
\hline 1 & 2 & 3 & 4 & 1.90 \\
\hline 1 & 2 & 3 & 4 & 2.90 \\
\hline 1 & 2 & 3 & 4 & 2.90 \\
\hline 1 & 2 & 3 & 4 & 3.20 \\
\hline & 2 & 3 & 4 & 1.90 \\
\hline
\end{tabular}

1. How does automation improve the quality of the final design and drawings?

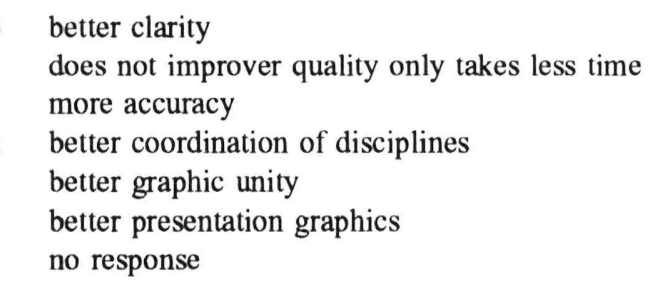




\section{Comments:}

- Automation improves the clarity of the job, TIME improves the quality

- Doesn't, the quality in not what automation is meant to improve. Quality is either there or not whether or not automation is used. Time is the issue and that has been reduced only slightly

- Line work quality better

- Finished drawings are covered with eraser smudges

- Drawings are more accurate and easier to read

- See answer to 1 st question on this page. Also archiving as built for future use are probably more accurate. Overall accuracy

- If allows better coordination and cross discipline checking

- Graphic uniformity

- Consistent, clean, precise

- Once you have developed the "look" you want you need not concern yourself with the problem, more time is spent on the design rather worrying about line weight

- Consistence within and among disciplines

- Sometimes-through 3D modeling and more options

2. When using computers in the design process, does the ability to quickly develop alternatives affect the way you design? If so, how?

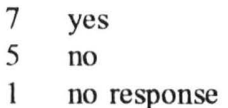

\section{Comments:}

- By mirroring, copying, rotating

- Alternatives are not generated any faster

- Alternative schemes can be easily generated by flip flopping modules etc.

- Assuming alternative are quickly developed, several design solutions can be presented to the client in a clear manner. Both parties can discuss the pros and cons of each solution

- Yes, it allows one to come up with more alternatives in a shorter period of time

- Only permits me to explore more alternatives

- Yes, I have a tendency to explore and develop more alternatives both in plan and elevation

- Yes, put out more alternatives

3. Describe how solid modeling (3D viewing ) helps or hinders the design process?

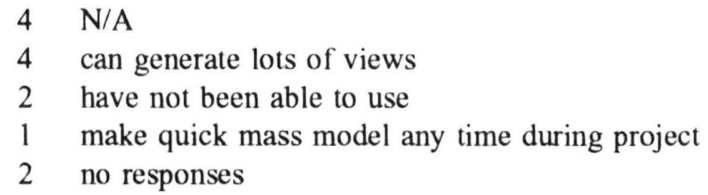

\section{Comments:}

- It helps by providing a basis for generating numerous views in perspective and for animated walk-through of a space

- I have not implemented 3D as of yet but plan to in the future. I believe it will help

- It can help the design process by allowing one to quickly view a model of ones design and study different alternatives

- Helps, allows massing models to be created quickly at any time in the design process

- Never been able to use

- It helps by providing a real world view of possible alternatives

- Helps Allows more design in 3D, once model is built, can look at it from any angle and make appropriate adjustments

\section{Automated drafting}

time spent drafting? _59.6_ percent on design? _40.0_ percent

\section{Manual drafting}

time spent drafting? _31.9_ percent on design? _32.7_ percent 


\section{DISTRIBUTION}

Chief of Engineers

ATTN: CEHEC-IM-LH (2)

ATTN: CEHEC $\cdot$ IM-LP (2)

ATTN: CERD-L

ATTN: CEMP-EA

Fort Belvoir, VA 22060

ATTN: CECC-R

Defense Technical Info. Center 22304

ATTN: DTIC-FAB (2)

9

$9 / 92$ 



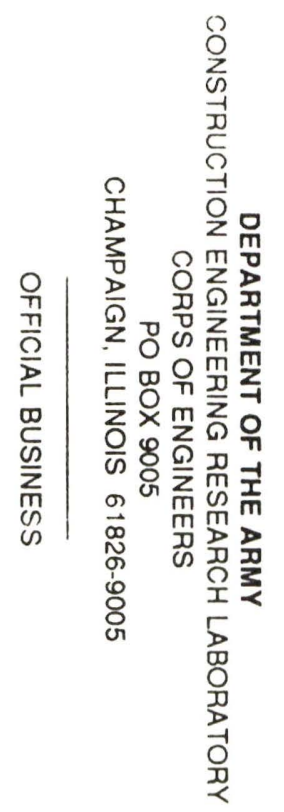

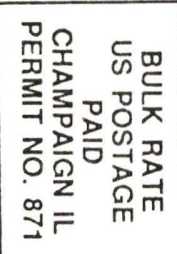

